Abstract

Background. We describe a study to assess the precision of the GE Lunar iDXA and the agreement between the iDXA and GE Lunar Prodigy densitometers for measurement of regional and total body bone and body composition in normal to obese healthy adults. We

compare the whole body fat mass by DXA to measurements by a four component (4-C)

6 model.

7 Methods. Sixty nine participants, aged $37 \pm 12$ years, BMI $26.2 \pm 5.1 \mathrm{~kg} / \mathrm{cm}^{2}$, were measured once on the Prodigy and twice on the iDXA. The 4-C model estimated fat mass from body mass, total body water by deuterium dilution, body volume by air displacement plethysmography and bone mass by DXA. Agreement between measurements made on the two instruments and by the 4-C model were analysed by Bland-Altman and linear regression. Where appropriate translational cross-calibration equations were derived. Differences between DXA software versions were investigated.

Results. iDXA precision was less than $2 \%$ of the measured value for all regional and whole body bone and body composition measurements with the exception of arm fat mass (2.28\%). We found signifcant differences between iDXA and Prodigy $(P<0.05)$ whole body and regional bone, fat (FM) and lean mass (LM), with the exception of hip bone mass, area and density and spine area. Compared to iDXA, Prodigy over-estimated FM and underestimated LM. However, compared to 4-C, iDXA showed a smaller bias and narrower limits of agreement than Prodigy. No significant differences between software versions in FM estimations existed.

Conclusion. Our results demonstrate excellent iDXA precision. However significant differences exist between the two GE Lunar instruments, Prodigy and iDXA measurement values. A divergance from the reference $4-C$ observations remains in FM estimations made by DXA even following the recent advances in technology. Further studies are particularly warranted in individuals with large fat mass content.

\title{
Key words.
}

Body composition; DXA; fat mass; four-component model; total body water; precision; accuracy. 
Dual-energy X-ray absorptiometry (DXA) is widely used for bone density measurements within the clinical environment. Within the research community there is perhaps more emphasis on body composition measurement, driven by the increasing prevalence of obesity. In both contexts the ability to detect changes in measurements is arguably of more interest than the absolute value of the measurement so that an apparent change in bone or fat mass should not be generated and interpreted falsely.

DXA instruments have improved over time, most evidently in reduced scan times. As the technology has matured the focus of development has shifted to image quality, which has improved through advances in detector design yielding a higher pixel density. Major benefits of this are better discrimination of bone edges and better imaging of soft tissue, particularly in the thoracic region [1]. Both translate to improved repeated measures precision [2, 3]. These benefits come at the cost of a new instrument, compounded by the complexities of managing the migration from old to new which involve performing crosscalibration assessments to identify any differences between instruments and account for them using translational regression equations [4].

The iDXA is the latest densitometer to come from GE Lunar, a development of the GE Lunar Prodigy and Prodigy Advance. A new detector and x-ray filter (producing different energy spectra) provide improved resolution and image quality by better bone edge detection [1]. This also suggests there may be improved soft tissue algorithms within the software compared to previous instruments. Repeated measures precision describes the variability between two measurements caused the instrument itself, by re-positioning and by operator error and so sets the threshold for discriminating biological change between two measurements [5]. Several authors have documented the iDXA's enhanced precision for repeated measures compared to previous models [2, 3, 6].

Here we report an investigation which extends the previously reported work. The primary purpose of this study is to evaluate the precision and accuracy of the iDXA. Secondly we aim to produce translational regression equations for relating scans between the Lunar Prodigy and iDXA. Further, we have determined accuracy of iDXA measured fat mass measurement by comparison with a four-component model (4-C) [7]. The 4-C model is widely accepted as a reference against which the accuracy of other body composition methodologies is evaluated.

\section{Material and Method}

Participants

Sixty nine healthy men $(n=33)$ and women $(n=36)$ were recruited for the purposes of this study. Two participants were excluded from the hip analysis, one for poor positioning and 

one for an artificial joint. One participant was excluded from the total body water analysis because of an insufficient sample volume. The demographic data of the cohort is presented in Table 1. All participants were made aware of the risks associated with the measurements and provided informed consent in writing. Participants were healthy, free from disease and non-smoking; they were excluded if they were pregnant or receiving any metabolisminfluencing medications. The study was approved by the Cambridge Central Ethics

75 Committee.

Each participant arrived at NIHR/Wellcome Trust Clinical Research Facility, Addenbrooke's biomedical campus, Cambridge at noon on the day of their visit to undertake three procedures: whole body water determination using deuterium dilution; DXA; and body volume determination using air displacement plethysmography (ADP). The participants wore light, metal-free clothing and refrained from food and drink for $30 \mathrm{~min}$ before and during the measurements.

82 Insert Table 1. 
Protocol

\section{Deuterium dilution}

A baseline saliva sample was obtained from the participant shortly after arrival. Height was measured on a stadiometer and recorded to the nearest millimetre (SECA 242 digital stadiometer, Seca, Hamburg, Germany). Weight was measured on electronic scales to the nearest gram (Kern \& Sohn GmbH, Germany) for dose calculation only. The participant then consumed a dose of $70 \mathrm{mg}$ per $\mathrm{kg}$ body mass of ${ }^{2} \mathrm{H}_{2} \mathrm{O}$ (99.8\%, CK Isotopes Ltd., Ibstock, Leicestershire, UK) [8]. Further $1 \mathrm{ml}$ saliva samples were collected at 3,4 and 5 hours post dose. Food and drink were withheld for $30 \mathrm{~min}$ prior to the collection of each saliva sample. The saliva samples were frozen at $-20^{\circ} \mathrm{C}$ until later analysis using dual inlet isotope ratio mass spectrometry (Isoprime, GV Instruments, Wythenshawe, UK).

\section{DXA}

Each participant was scanned twice on the iDXA (GE Healthcare Lunar, Maddison, WI, USA, EnCore software version 16 (enhanced analysis)), with repositioning in between scans, and once on the GE Lunar Prodigy (EnCore software version 12.3). The Prodigy data (basic analysis) was re-analysed on the iDXA using software version 16 to provide enhanced Prodigy analysis. All three scans were performed on the same day by the same operator. Sites scanned were hip (left femur) and lumbar spine (L2-L4) for bone mass, area and density and whole-body for both whole body bone mass, area and density and body composition. Calibration block quality assurance and encapsulated spine phantom quality control scans were performed on each instrument at the start of each scanning day.

The scans were performed by three trained operators who performed scans according to the manufacturers positioning and scanning protocols (Precision for each operator, represented by \%CV of repeated scans, ranged from $0.7 \%$ to $1.5 \%$ for lumbar spine and 0.5 $\%$ to $1.0 \%$ for total hip, below the recommended $1.9 \%$ for lumbar spine and $1.8 \%$ for total hip by the International Society of Clinical Densitometry (ISCD) [4]). Subsequent analysis of all scans was carried out by a single operator to ensure consistency throughout the study.

\section{Air displacement plethysmography}

The participants were asked to pass urine before the ADP procedure (BODPOD ${ }^{\circledR}$, Cosmed Srl, Rome, Italy). Tight fitting swim wear and a swimming cap were worn to minimise air trapped in clothing and hair. Lung volume was estimated by the BODPOD software to provide a net body volume estimate. The weight obtained during the ADP procedure was used as the body mass value for the total body water and $4-C$ analysis. 


\section{Analysis and Calculations}

\section{TBW plateau method}

TBW was calculated according to the method of [8]. In brief, aliquots of $0.2 \mathrm{ml}$, drawn from the saliva samples were placed in $3.7 \mathrm{ml}$ glass bottles with rubber septa (non-evacuated vials, Labco Ltd, Lampeter, UK) and equilibrated with hydrogen in the presence of a platinum catalyst. Data was drift corrected off-line and all measurements were made relative to Vienna standard mean ocean water (V-SMOW) using laboratory standards traceable to the international standard.

${ }^{2} \mathrm{H}_{2} \mathrm{O}$ dilution space was determined using the following equation [9]:

$$
\left.{ }^{2} H_{2} O(k g)\right)=\left[\frac{D \times T \times(E d-E t)}{d \times(E s-E p)}\right] / 1000
$$

Where: $D$ is the amount of oral dosing solution, in grams, administered to the subject; $T$ is the amount of deionised tap water used to dilute the enriched isotope dose, in grams; $d$ is the amount of enriched isotope dose in grams.

$E d$ is enrichment of the diluted dose $d$ in $\mathrm{T}$; Et is the enrichment of the tap water diluent; $E s$ is the mean enrichment of saliva samples at 3, 4 and 5 hours; Ep is the enrichment of the pre dose sample.

Total body water (TBW (kg)) was then calculated by reducing ${ }^{2} \mathrm{H}_{2} \mathrm{O}$ dilution space values by $4 \%$ to account for the exchange of deuterium with non-aqueous hydrogen [10].

Four component model (4-C)

Fat mass (FM, kg) using the 4-C model was calculated using the following equation of Fuller et al [7]:

$$
F M=2.747 \times B V-0.710 \times T B W-1.460 \times B M C-2.050 \times B W
$$

Where: BV is body volume and determined using ADP; TBW is total body water and determined using deuterium dilution; $\mathrm{BMC}$ is whole body bone mineral content and determined using DXA and BW is body weight determined during the ADP procedure.

\section{Statistical analysis}

Descriptive data are reported as mean \pm (standard deviation) unless otherwise stated. Analysis revealed the body composition data was normally distributed.

Precision of the iDXA was expressed as the root mean square standard deviation (RMS-SD) and \% CV according to ISCD recommendations. Least significant change (LSC) was calculated ( $2.77 \times$ RMS-SD) to establish the smallest change between repeated scans which could be identified with $95 \%$ confidence as originating from the participant rather than instrument and positioning variability [5].

Paired sample t tests were performed to determine the difference between instruments 
Bland-Altman analysis was performed to determine the association and agreement between the two instruments and between each instrument and 4-C derived fat mass. Where appropriate linear regression analysis was used to derive cross-calibration equations between Prodigy data, using enhanced analysis mode and iDXA data. It should be noted that enhanced analysis mode is only available on Lunar Prodigy Advanced and iDXA instruments running software versions 15 and 16. If an earlier version of the Lunar Prodigy instrument is being used, refer to supplementary data where we have given whole body and regional bone and body composition cross-calibration regression equations to translate from Lunar Prodigy measurements analysed in basic mode to Lunar iDXA measurements.

Repeated measures ANOVA was applied to test for significance in fat measurements. Post hoc comparisons with Bonferroni correction were applied to discover significance between methods (4-C, iDXA, Prodigy Enhanced and Prodigy Basic). iDXA values were calculated as the mean of two iDXA measurements.

GraphPad Prism (Version 6.00 for Windows, GraphPad Software, San Diego California USA) was used to generate Bland-Altman analyses and IBM SPSS (IBM Corp. Released 2012. IBM SPSS Statistics for Windows, Version 21.0. Armonk, NY: IBM Corp) was used for all other statistical analyses.

Significance was assumed for $p<0.05$ for statistical tests other than ANOVA.

Results

iDXA precision

Precision error for repeated iDXA scans is shown in Table 2. Precision error, when represented by $\% \mathrm{CV}$, was less than $2 \%$ for all measures with the exception of arm fat mass (2.3\%).

Insert Table 2.

\section{iDXA fat mass accuracy}

iDXA measured fat mass and 4-C derived fat mass are highly correlated $\left(r^{2}=0.99, P<0.05\right)$ with a slope of 0.892 and an intercept of 3.39. However, there is a significant difference between iDXA measured fat mass and 4-C derived fat mass (mean difference (SD), -0.9 (1.8), $P<0.05)$ with wide limits of agreements $(-4.5-2.7)$. It can be seen in Figure 1 that there is a significant positive proportional bias and systematic bias. Furthermore, at an average fat mass of $32.1 \mathrm{~kg}$ the iDXA shifted from over-measuring to under-measuring fat mass compared to $4-C$ derived fat mass. 
Insert Figure 1

\section{iDXA vs Prodigy}

There were significant differences in whole body and spine bone masses between iDXA and Prodigy enhanced measurements, these differences were not seen in any hip measurements (Table 3).

The comparison of body composition measurements between the instruments reveals significant differences in fat and lean masses across all regions (Table 4).

Differences in whole body and regional bone and body composition measurements between Prodigy basic mode and iDXA enhanced mode analyses are presented in supplementary table 1 . The relevant cross-calibration regression equations can be found in supplementary tables 2 and 3.

Insert Table 3.

Insert Table 4.

Insert Figure 2

Figure 2 illustrates the agreement between instruments in fat mass and lean mass by BlandAltman analysis. Compared to iDXA, Prodigy overestimates fat mass (mean difference -1.3 $\mathrm{kg}$ ) and underestimates lean mass (mean difference $1.2 \mathrm{~kg}$ ).

Due to the observed differences between instruments (Table 3 and Table 4) linearregression cross-calibration equations were derived where appropriate and can be seen in Table 5.

\section{Insert Table 5.}

\section{Prodigy Accuracy}

Prodigy enhanced fat mass and 4-C derived fat mass are highly correlated $\left(R^{2}=0.993\right)$, with a slope of 0.883 and intercept of 4.80 . As observed with the iDXA (Figure 1), there is a significant difference between Prodigy enhanced fat mass and 4-C fat mass (mean difference (SD) $-2.2(2.1) \mathrm{kg}$ ). There are also wider limits of agreement $(-6.2-1.9)$ and a more negative systematic bias than for the iDXA (Figure $3 b \& 3 c$ )

\section{Four method comparison}

Insert Figure 3.

The measurement of fat mass was significantly affected by method $(F(3,201)=41.057, P$ $<0.05$ ). There was a significant difference between $4-C$ derived fat mass and iDXA (mean diff $-0.936, \mathrm{P}=0.000)$, Prodigy Enhanced $(-2.157, \mathrm{P}=0.000)$ and Prodigy Basic $(-1.720, \mathrm{P}=0.000)$ 
221 fat mass. However, there was no significant difference between Prodigy basic and Prodigy 222 enhanced fat mass measurements $(0.437, \mathrm{P}=0.275)$. 
Discussion

The aim of this study was two-fold: firstly, to determine the precision and accuracy of the GE Lunar iDXA and secondly, to determine if cross-calibration equations are necessary to relate data from the GE Lunar Prodigy to the iDXA densitometers. The difference between software versions for the Prodigy were also investigated.

When introducing a new DXA instrument the ISCD recommend that a crosscalibration of at least 30 participants, representative of the facility's patient population, should be performed. Participants should be scanned twice on the new system and once on the old, on those anatomical sites most commonly measured [4]. We compared the iDXA and Prodigy densitometers for regional and whole body bone mineral density, bone mineral content and bone area and, reflecting our interest in body composition, for lean and fat mass. Where cross-calibration equations were deemed necessary they were derived using linear regression.

\section{iDXA Precision}

Precision of the iDXA was assessed by \%CV of repeated bone and body composition measurements. We found excellent precision in whole body and regional bone density with all values below $2 \%$. This was also observed for whole body and regional body composition measurements with the exception of arm fat mass, which had a lower precision of $2.28 \%$.

Our findings support previously published literature which has reported similar precision data for whole body and regional bone density and body composition using iDXA [2, 3, 11, 12]. Additionally, both Rothney et al [11] and Kaminsky et al [12] support our findings of a lower precision in arm fat mass (2.8\% and $4.2 \%$ Rothney and Kaminsky respectively). The larger precision error may be due to re-positioning of the participants or the inclusion of breast tissue in the arm region of interest in some re-scans therefore offering the potential for larger errors [13].

Compared to the iDXA, previously published reports from its predecessor, the Prodigy have demonstrated similar precision for bone density with precisions reported below $2 \%$ by Oldroyd et al [14] and Krueger et al [15]. However, when exploring body composition, both Oldroyd et al and Bilsborough et al [16] reported whole body fat mass precision values of $2.5 \%$ for Prodigy. This is a much lower precision than that of $0.9 \%$ for the iDXA in the current study.

These comparisons suggest that the precision of iDXA when measuring bone density remains similar to the Prodigy. However, there appears to be a worthwhile improvement in precision in whole body and regional fat mass. This may be due to the improvement in soft tissue assessment as a result of enhanced bone edge detection technology [17].

\section{iDXA vs Prodigy}

When scan analysis was carried out using the same software version, significant differences between iDXA and Prodigy were identified in all regions of bone mass, area and density except for the femoral hip BMD and lumbar spine (L2-L4) BA, with Prodigy over- 
reading all values with the exception of hip area. This has been similarly observed in other studies [18-20] with Hull et al [19] reporting significantly higher mean BMC values in the Prodigy than the iDXA in both males and females (males; $3.11 \mathrm{~kg} v \mathrm{vs.} 3.06 \mathrm{~kg}$, Prodigy vs. iDXA respectively and females; $2.37 \mathrm{~kg} v \mathrm{vs} .2 .31 \mathrm{~kg}$, Prodigy vs. iDXA respectively). Rhodes et al [20] also found Prodigy BMC values were significantly higher compared to the iDXA in all regions of bone mass (BMC, $2842 \mathrm{~g}$ vs. $2651 \mathrm{~g}$, Prodigy vs. iDXA respectively). Furthermore, Morrison et al [21] compared iDXA to Prodigy and found significant differences in whole body and regional bone density (mean whole body; $1.25 \mathrm{~g} / \mathrm{cm}^{2} \mathrm{vs.} 1.22 \mathrm{~g} / \mathrm{cm}^{2}$, Prodigy vs. iDXA respectively)

When investigating body composition, we also observed significant differences between iDXA and Prodigy with Prodigy tending to over-read fat mass and under-read lean mass relative to iDXA. The only study we found in the literature to make a similar comparison was that of Morrison et al [21] who reported that only leg lean mass and arm soft tissue measurements were significantly different between instruments (leg lean mass mean difference (kg); 0.586, arm fat mass; -0.109, arm lean mass; -0.228).

The significant differences observed between the two DXA instruments warranted the development of cross-calibration regression equations. The differences and those observed across the published literature highlight the importance of generating instrument specific cross-calibration equations when undergoing a system upgrade. It is also important that the cross-calibration equations are relevant to the population under investigation as demonstrated by the apparent outliers at the top end of the fat mass range.

\section{DXA accuracy}

The accuracy of our DXA fat mass measurements was evaluated by comparing fat mass estimated by DXA to that derived from a four-component (4-C) model. The 4-C model, as well as whole body $\mathrm{MRI}$, are recognised standards in body composition measurements as they account for inter-individual variability in total body water and bone mineral mass [2224]. Our results demonstrated good correlation between iDXA and 4-C derived fat mass ( $r=$ 0.994 ) but a systematic bias between the two fat mass estimates was evident. To our knowledge there is no literature that discusses the accuracy of either iDXA or Prodigy fat mass measurement using the $4-\mathrm{C}$ model. However, previous literature has reported significant differences between fat mass (\%) measured by various DXA models (QDR2000, QDR2000W, DPX/L, and Lunar) and the 4-C model [25]. When comparing Prodigy and the 4C model, Williams et al [25] found significant differences in fat mass $(1.35,1.21$ and $1.58 \mathrm{~kg}$ in non-obese men, women and obese women, respectively). They also reported that the fat mass bias was positively associated with BMI. Although it appears that the accuracy of DXA has improved over the years, a systematic bias still remains between the iDXA and the 4-C model.

The differences identified between the two methods could have several origins. DXA assumes that the hydration value for fat-free mass remains constant [26], however this may 
not be true for participants across a range of masses. Participant mass itself may inflict a bias in soft tissue estimation because of the influence of tissue depth on bone edge detection by DXA, therefore as subject mass increases, so may the error in detecting soft tissue. Although $4-\mathrm{C}$ is considered a reference measure against other methods there is still concern that errors arising from the individual methods may amalgamate to a large error in the final fat mass estimate. However, Fuller et al found a measurement error of less than $1 \%$ for fat and fat free mass derived from 4-C.

Comparisons between GE software versions (Basic and Enhanced) for Prodigy and a 4-C model have not been investigated before. There are many publications that demonstrate the transitions between instruments, but few that detail the differences when upgrading software versions. In the final part of this study we investigated the differences in whole body fat mass measurements between basic and enhanced software versions on the Prodigy and compared this to the iDXA and 4-C model.

Prodigy basic analysis mode compared to 4-C demonstrated a good agreement over a wide range of fat masses. However, in the highest fat masses the agreement was less good, consistent with previous studies [25, 27, 28]. As referred to earlier, Williams et al [25] reported the largest difference between 4-C and Prodigy (Encore 2002) in obese women (mean bias $1.58 \mathrm{~kg}$ ) and Wells et al [27] (Software version not stated), reported that Prodigy significantly over-estimated FM compared to $4-\mathrm{C}$ by $0.9 \mathrm{~kg}$ with the greatest variability being observed at the highest fat masses.

In summary, the latest DXA instrument from GE, the iDXA, comes with new hardware in the form of a more powerful X-ray tube, enhanced image resolution and therefore better bone edge detection. Furthermore the latest software, Encore version $15 \& 16$, comes with developed soft tissue algorithms. This enhancement in technology has led to an improvement in both accuracy and precision of the new instrument. However this means that differences exist between the iDXA and Prodigy instruments and therefore crosscalibration equations are essential if comparisons between instruments are unavoidable. Even with these improvements, accuracy issues remain at the highest fat masses, reinforcing the importance of deriving cross-calibration equations that are relevant to the population under investigation and also that further comparative studies are warranted in an obese population. 
334 The authors declare no conflict of interest

\section{Acknowledgements}

336 LPEW and PRM are supported by the NIHR/Wellcome Trust Clinical Research Facility

337 Cambridge. MCV is supported by the MRC Elsie Widdowson Laboratory (Programme

338 numbers: Physiological Modelling of Metabolic Risk, MC_UP_A090_1005, and Nutrition,

339 Surveys and Studies, MC_U105960384).

340 The authors would like to thank all of our participants without whom we could not have 341 completed this study. We would also like to thank: Katie Bird and Liz Blower at the

342 NIHR/Wellcome Trust Clinical Research Facility for their assistance with the DXA

343 measurements and dose administration and Priya Singh, Elise Orford and David Collins at

344 the Medical Research Council (MRC) Elsie Widdowson Laboratory for their assistance in the 345 deuterium analysis and statistical analysis. Of course we will remain forever indebted to $\mathrm{Dr}$ 346 Les Bluck for all of his scientific excellence and help in conceptualising the study and many 347 other worthy contributions before his untimely death.

\section{Author Contributions}

349 The authors responsibilities were as follows: LW - study concept and design, conducted 350 research, analysis and interpretation of data, drafted manuscript, and primary responsibility 351 for the final content, MV - critical revision of the manuscript and important intellectual contributions, PRM - critical revision of the manuscript and important intellectual contributions. All authors read and approved the final manuscript. 
355 1. Toombs, R.J., et al., The impact of recent technological advances on the trueness and precision of DXA to assess

body composition. Obesity (Silver Spring), 2012. 20(1): p. 30-9.

2. Hind, K., B. Oldroyd, and J.G. Truscott, In vivo precision of the GE Lunar iDXA densitometer for the measurement of total body composition and fat distribution in adults. Eur J Clin Nutr, 2011. 65(1): p. 140-2.

3. Hind, K., B. Oldroyd, and J.G. Truscott, In vivo precision of the GE Lunar iDXA densitometer for the measurement of total-body, lumbar spine, and femoral bone mineral density in adults. J Clin Densitom, 2010. 13(4): p. 413-7.

4. Shepherd, J.A., et al., Cross-calibration and minimum precision standards for dual-energy X-ray absorptiometry: the 2005 ISCD Official Positions. J Clin Densitom, 2006. 9(1): p. 31-6.

5. Baim, S., et al., Precision assessment and radiation safety for dual-energy X-ray absorptiometry: position paper of the International Society for Clinical Densitometry. J Clin Densitom, 2005. 8(4): p. 371-8.

6. Chen, X., N. Iqbal, and G. Boden, The effects of free fatty acids on gluconeogenesis and glycogenolysis in normal subjects. J Clin Invest, 1999. 103(3): p. 365-72.

7. Fuller, N.J., et al., Four-component model for the assessment of body composition in humans: comparison with alternative methods, and evaluation of the density and hydration of fat-free mass. Clin Sci (Lond), 1992. 82(6): $p$. 687-93.

8. IAEA, Assessment of Body Composition and Total Energy Expenditure in Humans Using Stable Isotope Techniques, in IAEA Human Health Series. 2009: Vienna. p. 146.

9. Coward, W.A., Measurement of energy expenditure: the doubly-labelled-water method in clinical practice. Proc Nutr Soc, 1991. 50(2): p. 227-37.

10. Schoeller, D.A. and J.M. Hnilicka, Reliability of the doubly labeled water method for the measurement of total daily energy expenditure in free-living subjects. J Nutr, 1996. 126(1): p. 348S-354S.

11. Rothney, M.P., et al., Precision of GE Lunar iDXA for the measurement of total and regional body composition in nonobese adults. J Clin Densitom, 2012. 15(4): p. 399-404.

12. Kaminsky, L.A., et al., Precision of total and regional body fat estimates from dual-energy X-ray absorptiometer measurements. J Nutr Health Aging, 2014. 18(6): p. 591-4.

13. Knapp, K.M., et al., Obesity increases precision errors in total body dual-energy $x$-ray absorptiometry measurements. J Clin Densitom, 2015. 18(2): p. 209-16.

14. Oldroyd, B., A.H. Smith, and J.G. Truscott, Cross-calibration of GE/Lunar pencil and fan-beam dual energy densitometers--bone mineral density and body composition studies. Eur J Clin Nutr, 2003. 57(8): p. 977-87.

15. Krueger, D., et al., BMD measurement and precision: a comparison of GE Lunar Prodigy and iDXA densitometers. J Clin Densitom, 2012. 15(1): p. 21-5.

16. Bilsborough, J.C., et al., The accuracy and precision of DXA for assessing body composition in team sport athletes. J Sports Sci, 2014. 32(19): p. 1821-8.

17. Healthcare, G., Lunar iDXA: Intelligent DXA, G. Healthcare, Editor. 2006: Belgium. p. 10.

18. Hind, K., et al., A cross-calibration study of the GE-Lunar iDXA and prodigy for the assessment of lumbar spine and total hip bone parameters via three statistical methods. J Clin Densitom, 2015. 18(1): p. 86-92.

19. Hull, H., et al., iDXA, Prodigy, and DPXL dual-energy X-ray absorptiometry whole-body scans: a cross-calibration study. J Clin Densitom, 2009. 12(1): p. 95-102.

20. Rhodes, L.A., et al., Cross-calibration of a GE iDXA and Prodigy for total and regional body bone parameters: the importance of using cross-calibration equations for longitudinal monitoring after a system upgrade. J Clin Densitom, 2014. 17(4): p. 496-504.

21. Morrison, S.A., et al., Comparison of the Lunar Prodigy and iDXA Dual-Energy X-ray Absorptiometers for Assessing Total and Regional Body Composition. J Clin Densitom, 2016. 19(3): p. 290-7.

22. Lohman, T.G., et al., Assessing body composition and changes in body composition. Another look at dual-energy X-ray absorptiometry. Ann N Y Acad Sci, 2000. 904: p. 45-54.

23. Muller, M.J., et al., Application of standards and models in body composition analysis. Proc Nutr Soc, 2016. 75(2): p. 181-7.

24. Heymsfield, S.B., et al., Multi-component molecular-level body composition reference methods: evolving concepts and future directions. Obes Rev, 2015. 16(4): p. 282-94.

25. Williams, J.E., et al., Evaluation of Lunar Prodigy dual-energy X-ray absorptiometry for assessing body composition in healthy persons and patients by comparison with the criterion 4-component model. Am J Clin Nutr, 2006. 83(5): p. 1047-54.

26. Wang, Z., et al., Hydration of fat-free body mass: review and critique of a classic body-composition constant. Am J Clin Nutr, 1999. 69(5): p. 833-41.

27. Wells, J.C., et al., Body-composition reference data for simple and reference techniques and a 4-component model: a new UK reference child. Am J Clin Nutr, 2012. 96(6): p. 1316-26.

28. Wells, J.C., et al., Body composition in young female eating-disorder patients with severe weight loss and controls: evidence from the four-component model and evaluation of DXA. Eur J Clin Nutr, 2015. 69(12): p. 1330-5. 
An investigation into the differences in bone density and body composition measurements between two GE Lunar densitometers and their comparison to a four component model.

Laura PE Watson $^{1}$, Michelle C Venables ${ }^{2}$, Peter R Murgatroyd ${ }^{1}$

${ }^{1}$ From the NIHR/Wellcome Trust Clinical Research Facility, Addenbrooke's Hospital, Cambridge, UK (LW, PRM), ${ }^{2}$ MRC-Human Nutrition Research, Elsie Widdowson Laboratory, Cambridge UK (MV)

${ }^{1}$ Address correspondence to Laura Watson, NIHR/Wellcome Trust Clinical Research Facility, Box 127, Addenbrooke’s Hospital, Cambridge, UK. E-mail: Ipew2@medschl.cam.ac.uk

Telephone + +441223596077

Fax $\quad+441223596059$

Running head: DXA precision and accuracy. 
2 Background. We describe a study to assess the precision of the GE Lunar IDXA and the 3 agreement between the iDXA and GE Lunar Prodigy densitometers for measurement of 4 regional and total body bone and body composition in normal to obese healthy adults. We

5 compare the whole body fat mass by DXA to measurements by a four component (4-C) 6 model.

7 Methods. Sixty nine participants, aged $37 \pm 12$ years, BMI $26.2 \pm 5.1 \mathrm{~kg} / \mathrm{cm}^{2}$, were measured 8 once on the Prodigy and twice on the iDXA. The 4-C model estimated fat mass from body 9 mass, total body water by deuterium dilution, body volume by air displacement 10 plethysmography and bone mass by DXA. Agreement between measurements made on the two instruments and by the 4-C model were analysed by Bland-Altman and linear regression. Where appropriate translational cross-calibration equations were derived. Differences between DXA software versions were investigated.

Results. iDXA precision was less than $2 \%$ of the measured value for all regional and whole body bone and body composition measurements with the exception of arm fat mass (2.28\%). We found signifcant differences between iDXA and Prodigy $(P<0.05)$ whole body and regional bone, fat (FM) and lean mass (LM), with the exception of hip bone mass, area and density and spine area. Compared to iDXA, Prodigy over-estimated FM and underestimated LM. However, compared to 4-C, iDXA showed a smaller bias and narrower limits of agreement than Prodigy. No significant differences between software versions in FM estimations existed.

Conclusion. Our results demonstrate excellent iDXA precision. However significant differences exist between the two GE Lunar instruments, Prodigy and iDXA measurement values. A divergance from the reference 4-C observations remains in FM estimations made by DXA even following the recent advances in technology. Further studies are particularly warranted in individuals with large fat mass content.

Key words.

Body composition; DXA; fat mass; four-component model; total body water; precision; 
Dual-energy X-ray absorptiometry (DXA) is widely used for bone density measurements within the clinical environment. Within the research community there is perhaps more emphasis on body composition measurement, driven by the increasing prevalence of obesity. In both contexts the ability to detect changes in measurements is arguably of more interest than the absolute value of the measurement so that an apparent change in bone or fat mass should not be generated and interpreted falsely.

DXA instruments have improved over time, most evidently in reduced scan times. As the technology has matured the focus of development has shifted to image quality, which has improved through advances in detector design yielding a higher pixel density. Major benefits of this are better discrimination of bone edges and better imaging of soft tissue, particularly in the thoracic region [1]. Both translate to improved repeated measures precision [2, 3]. These benefits come at the cost of a new instrument, compounded by the complexities of managing the migration from old to new which involve performing crosscalibration assessments to identify any differences between instruments and account for them using translational regression equations [4].

The iDXA is the latest densitometer to come from GE Lunar, a development of the GE Lunar Prodigy and Prodigy Advance. A new detector and x-ray filter (producing different energy spectra) provide improved resolution and image quality by better bone edge detection [1]. This also suggests there may be improved soft tissue algorithms within the software compared to previous instruments. Repeated measures precision describes the variability between two measurements caused the instrument itself, by re-positioning and by operator error and so sets the threshold for discriminating biological change between two measurements [5]. Several authors have documented the iDXA's enhanced precision for repeated measures compared to previous models [2, 3, 6].

Here we report an investigation which extends the previously reported work. The primary purpose of this study is to evaluate the precision and accuracy of the iDXA. Secondly we aim to produce translational regression equations for relating scans between the Lunar Prodigy and iDXA. Further, we have determined accuracy of iDXA measured fat mass measurement by comparison with a four-component model (4-C) [7]. The 4-C model is widely accepted as a reference against which the accuracy of other body composition methodologies is evaluated.

\section{Material and Method}

Participants

Sixty nine healthy men $(n=33)$ and women $(n=36)$ were recruited for the purposes of this study. Two participants were excluded from the hip analysis, one for poor positioning and 

one for an artificial joint. One participant was excluded from the total body water analysis because of an insufficient sample volume. The demographic data of the cohort is presented in Table 1. All participants were made aware of the risks associated with the measurements and provided informed consent in writing. Participants were healthy, free from disease and non-smoking; they were excluded if they were pregnant or receiving any metabolisminfluencing medications. The study was approved by the Cambridge Central Ethics

75 Committee.

Each participant arrived at NIHR/Wellcome Trust Clinical Research Facility, Addenbrooke's biomedical campus, Cambridge at noon on the day of their visit to undertake three procedures: whole body water determination using deuterium dilution; DXA; and body volume determination using air displacement plethysmography (ADP). The participants wore light, metal-free clothing and refrained from food and drink for $30 \mathrm{~min}$ before and during the measurements.

82 Insert Table 1. 
Protocol

\section{Deuterium dilution}

A baseline saliva sample was obtained from the participant shortly after arrival. Height and weight were then measured. Height was measured on a stadiometer and recorded to the nearest millimetre (SECA 242 digital stadiometer, Seca, Hamburg, Germany). Weight was measured on electronic scales to the nearest gram (Kern \& Sohn $\mathrm{GmbH}$, Germany). The participant then consumed a dose of $70 \mathrm{mg}$ per $\mathrm{kg}$ body mass of ${ }^{2} \mathrm{H}_{2} \mathrm{O}(99.8 \%$, CK Isotopes Ltd., Ibstock, Leicestershire, UK) [8]. Further $1 \mathrm{ml}$ saliva samples were collected at 3, 4 and 5 hours post dose. Food and drink were withheld for $30 \mathrm{~min}$ prior to the collection of each saliva sample. The saliva samples were frozen at $-20^{\circ} \mathrm{C}$ until later analysis using dual inlet isotope ratio mass spectrometry (Isoprime, GV Instruments, Wythenshawe, UK).

\section{DXA}

Each participant was scanned twice on the iDXA (GE Healthcare Lunar, Maddison, WI, USA, EnCore software version 16 (enhanced analysis)), with repositioning in between scans, and once on the GE Lunar Prodigy (EnCore software version 12.3). The Prodigy data (basic analysis) was re-analysed on the iDXA using software version 16 to provide enhanced Prodigy analysis. All three scans were performed on the same day by the same operator. Sites scanned were hip (left femur) and lumbar spine (L2-L4) for bone mass, area and density and whole-body for both whole body bone mass, area and density and body composition. Calibration block quality assurance and encapsulated spine phantom quality control scans were performed on each instrument at the start of each scanning day.

The scans were performed by three trained operators who performed scans according to the manufacturers positioning and scanning protocols (Precision for each operator, represented by \%CV of repeated scans, ranged from $0.7 \%$ to $1.5 \%$ for lumbar spine and 0.5 $\%$ to $1.0 \%$ for total hip, below the recommended $1.9 \%$ for lumbar spine and $1.8 \%$ for total hip by the International Society of Clinical Densitometry (ISCD) [4]). Subsequent analysis of all scans was carried out by a single operator to ensure consistency throughout the study.

\section{Air displacement plethysmography}

The participants were asked to pass urine before the ADP procedure (BODPOD ${ }^{\circledR}$, Cosmed Srl, Rome, Italy). Tight fitting swim wear and a swimming cap were worn to minimise air trapped in clothing and hair. Lung volume was estimated by the BODPOD software to provide a net body volume estimate. The weight obtained during the ADP procedure was used as the body mass value for the $4-C$ analysis. 


\section{Analysis and Calculations}

\section{TBW plateau method}

TBW was calculated according to the method of [8]. In brief, aliquots of $0.2 \mathrm{ml}$, drawn from the saliva samples were placed in $3.7 \mathrm{ml}$ glass bottles with rubber septa (non-evacuated vials, Labco Ltd, Lampeter, UK) and equilibrated with hydrogen in the presence of a platinum catalyst. Data was drift corrected off-line and all measurements were made relative to Vienna standard mean ocean water (V-SMOW) using laboratory standards traceable to the international standard.

${ }^{2} \mathrm{H}_{2} \mathrm{O}$ dilution space was determined using the following equation [9]:

$$
\left.{ }^{2} H_{2} O(k g)\right)=\left[\frac{D \times T \times(E d-E t)}{d \times(E s-E p)}\right] / 1000
$$

Where: $D$ is the amount of oral dosing solution, in grams, administered to the subject; $T$ is the amount of deionised tap water used to dilute the enriched isotope dose, in grams; $d$ is the amount of enriched isotope dose in grams.

$E d$ is enrichment of the diluted dose $d$ in $\mathrm{T}$; Et is the enrichment of the tap water diluent; $E s$ is the mean enrichment of saliva samples at 3, 4 and 5 hours; Ep is the enrichment of the pre dose sample.

Total body water (TBW (kg)) was then calculated by reducing ${ }^{2} \mathrm{H}_{2} \mathrm{O}$ dilution space values by $4 \%$ to account for the exchange of deuterium with non-aqueous hydrogen [10].

Four component model (4-C)

Fat mass (FM, kg) using the 4-C model was calculated using the following equation of Fuller et al [7]:

$$
F M=2.747 \times B V-0.710 \times T B W-1.460 \times B M C-2.050 \times B W
$$

Where: BV is body volume and determined using ADP; TBW is total body water and determined using deuterium dilution; $\mathrm{BMC}$ is whole body bone mineral content and determined using DXA and BW is body weight determined during the ADP procedure.

\section{Statistical analysis}

Descriptive data are reported as mean \pm (standard deviation) unless otherwise stated.

Precision of the iDXA was expressed as the root mean square standard deviation (RMS-SD) and \% CV according to ISCD recommendations. Least significant change (LSC) was calculated ( $2.77 \times$ RMS-SD) to establish the smallest change between repeated scans which could be identified with $95 \%$ confidence as originating from the participant rather than instrument and positioning variability [5].

Paired sample t tests were performed to determine the difference between instruments. 
Bland-Altman analysis was performed to determine the association and agreement between the two instruments and between each instrument and 4-C derived fat mass. Where appropriate linear regression analysis was used to derive cross-calibration equations between Prodigy data, using enhanced analysis mode and iDXA data. It should be noted that enhanced analysis mode is only available on Lunar Prodigy Advanced and iDXA instruments running software versions 15 and 16. If an earlier version of the Lunar Prodigy instrument is being used, refer to supplementary data where we have given whole body and regional bone and body composition cross-calibration regression equations to translate from Lunar Prodigy measurements analysed in basic mode to Lunar iDXA measurements.

Repeated measures ANOVA was applied to test for significance in fat measurements. Post hoc comparisons with Bonferroni correction were applied to discover significance between methods (4-C, iDXA, Prodigy Enhanced and Prodigy Basic). iDXA values were calculated as the mean of two iDXA measurements.

GraphPad Prism (Version 6.00 for Windows, GraphPad Software, San Diego California USA) was used to generate Bland-Altman analyses and IBM SPSS (IBM Corp. Released 2012. IBM SPSS Statistics for Windows, Version 21.0. Armonk, NY: IBM Corp) was used for all other statistical analyses.

Significance was assumed for $p<0.05$ for all statistical tests.

\section{Results}

\section{iDXA precision}

Precision error for repeated iDXA scans is shown in Table 2. Precision error, when represented by $\% \mathrm{CV}$, was less than $2 \%$ for all measures with the exception of arm fat mass (2.28\%). A greater precision was demonstrated for lean mass compared to fat mass.

\section{Insert Table 2.}

\section{iDXA fat mass accuracy}

iDXA measured fat mass and 4-C derived fat mass are highly correlated $\left(r^{2}=0.99, P<0.05\right)$ with a slope of 0.892 and an intercept of 3.39. However, there is a significant difference between iDXA measured fat mass and 4-C derived fat mass (mean difference (SD), -0.936 (1.83), $P<0.05)$ with wide limits of agreements $(-4.53-2.65)$. It can be seen in Figure 1 that there is a significant positive proportional bias and systematic bias. Furthermore, at an average fat mass of $32.12 \mathrm{~kg}$ the iDXA shifted from over-measuring to under-measuring fat mass compared to $4-C$ derived fat mass. 
Insert Figure 1

\section{iDXA vs Prodigy}

There were significant differences in whole body and spine bone masses between iDXA and Prodigy enhanced measurements, these differences were not seen in any hip measurements (Table 3).

The comparison of body composition measurements between the instruments reveals significant differences in fat and lean masses across all regions (Table 4).

Differences in whole body and regional bone and body composition measurements between Prodigy basic mode and iDXA enhanced mode analyses are presented in supplementary table 1 . The relevant cross-calibration regression equations can be found in supplementary tables 2 and 3.

Insert Table 3.

Insert Table 4.

Insert Figure 2

Figure 2 illustrates the agreement between instruments in fat mass and lean mass by BlandAltman analysis. Compared to iDXA, Prodigy overestimates fat mass (mean difference -1.29 $\mathrm{kg}$ ) and underestimates lean mass (mean difference $1.18 \mathrm{~kg}$ ).

Due to the observed differences between instruments (Table 3 and Table 4) linearregression cross-calibration equations were derived where appropriate and can be seen in Table 5.

Insert Table 5.

\section{Prodigy Accuracy}

Prodigy enhanced fat mass and 4-C derived fat mass are highly correlated $\left(R^{2}=0.993\right)$, with a slope of 0.883 and intercept of 4.80 . As observed with the iDXA (Figure 1), there is a significant difference between Prodigy enhanced fat mass and 4-C fat mass (mean difference (SD) $-2.16(2.05) \mathrm{kg}$ ). There are also wider limits of agreement $(-6.17-1.86)$ and a more negative systematic bias than for the iDXA (Figure $3 b \& 3 c$ )

\section{Four method comparison}

Insert Figure 3.

The measurement of fat mass was significantly affected by method $(F(3,201)=41.057, P$ $<0.05$ ). There was a significant difference between $4-C$ derived fat mass and iDXA (mean diff $-0.936, \mathrm{P}=0.000)$, Prodigy Enhanced $(-2.157, \mathrm{P}=0.000)$ and Prodigy Basic $(-1.720, \mathrm{P}=0.000)$ 
220 fat mass. However, there was no significant difference between Prodigy basic and Prodigy 221 enhanced fat mass measurements $(0.437, \mathrm{P}=0.275)$.

222 Figure 3 does show that iDXA limits of agreement with 4-C $(-4.78,2.63)$ are narrower compared to Prodigy in basic mode $(-5.56,2.12)$ which in turn are narrower than Prodigy 224 enhanced mode $(-6.17,1.86)$. 
Discussion

The aim of this study was two-fold: firstly, to determine the precision and accuracy of the GE Lunar iDXA and secondly, to determine if cross-calibration equations are necessary to relate data from the GE Lunar Prodigy to the iDXA densitometers. The difference between software versions for the Prodigy were also investigated.

When introducing a new DXA instrument the ISCD recommend that a crosscalibration of at least 30 participants, representative of the facility's patient population, should be performed. Participants should be scanned twice on the new system and once on the old, on those anatomical sites most commonly measured [4]. We compared the iDXA and Prodigy densitometers for regional and whole body bone mineral density, bone mineral content and bone area and, reflecting our interest in body composition, for lean and fat mass. Where cross-calibration equations were deemed necessary they were derived using linear regression.

\section{iDXA Precision}

Precision of the iDXA was assessed by \%CV of repeated bone and body composition measurements. We found excellent precision in whole body and regional bone density with all values below $2 \%$. This was also observed for whole body and regional body composition measurements with the exception of arm fat mass, which had a lower precision of $2.28 \%$.

Our findings support previously published literature which has reported similar precision data for whole body and regional bone density and body composition using iDXA [2, 3, 11, 12]. Additionally, both Rothney et al [11] and Kaminsky et al [12] support our findings of a lower precision in arm fat mass (2.8\% and $4.2 \%$ Rothney and Kaminsky respectively). The larger precision error may be due to re-positioning of the participants or the inclusion of breast tissue in the arm region of interest in some re-scans therefore offering the potential for larger errors [13].

Compared to the iDXA, previously published reports from its predecessor, the Prodigy have demonstrated similar precision for bone density with precisions reported below $2 \%$ by Oldroyd et al [14] and Krueger et al [15]. However, when exploring body composition, both Oldroyd et al and Bilsborough et al [16] reported whole body fat mass precision values of $2.5 \%$ for Prodigy. This is a much lower precision than that of $0.9 \%$ for the iDXA in the current study.

These comparisons suggest that the precision of iDXA when measuring bone density remains similar to the Prodigy. However, there appears to be a worthwhile improvement in precision in whole body and regional fat mass. This may be due to the improvement in soft tissue assessment as a result of enhanced bone edge detection technology [17].

\section{iDXA vs Prodigy}

When scan analysis was carried out using the same software version, significant differences between iDXA and Prodigy were identified in all regions of bone mass, area and density except for the femoral hip BMD and lumbar spine (L2-L4) BA, with Prodigy over- 
reading all values with the exception of hip area. This has been similarly observed in other studies [18-20] with Hull et al [19] reporting significantly higher mean BMC values in the Prodigy than the iDXA in both males and females (males; $3.11 \mathrm{~kg} v s .3 .06 \mathrm{~kg}$, Prodigy vs. iDXA respectively and females; $2.37 \mathrm{~kg}$ vs. $2.31 \mathrm{~kg}$, Prodigy vs. iDXA respectively). Rhodes et al [20] also found Prodigy BMC values were significantly higher compared to the iDXA in all regions of bone mass (BMC, $2842 \mathrm{~g}$ vs. $2651 \mathrm{~g}$, Prodigy vs. iDXA respectively). Furthermore, Morrison et al [21] compared iDXA to Prodigy and found significant differences in whole body and regional bone density (mean whole body; $1.25 \mathrm{~g} / \mathrm{cm}^{2}$ vs. $1.22 \mathrm{~g} / \mathrm{cm}^{2}$, Prodigy vs. iDXA respectively)

When investigating body composition, we also observed significant differences between iDXA and Prodigy with Prodigy tending to over-read fat mass and under-read lean mass relative to iDXA. The only study we found in the literature to make a similar comparison was that of Morrison et al [21] who reported that only leg lean mass and arm soft tissue measurements were significantly different between instruments (leg lean mass mean difference $(\mathrm{kg})$; 0.586, arm fat mass; -0.109, arm lean mass; -0.228).

The significant differences observed between the two DXA instruments warranted the development of cross-calibration regression equations. The differences and those observed across the published literature highlight the importance of generating instrument specific cross-calibration equations when undergoing a system upgrade. It is also important that the cross-calibration equations are relevant to the population under investigation as demonstrated by the apparent outliers at the top end of the fat mass range.

\section{DXA accuracy}

The accuracy of our DXA fat mass measurements was evaluated by comparing fat mass estimated by DXA to that derived from a four-component (4-C) model. The 4-C model, as well as whole body MRI, are recognised standards in body composition measurements as they account for inter-individual variability in total body water and bone mineral mass [2224]. Our results demonstrated good correlation between iDXA and 4-C derived fat mass ( $r=$ 0.994 ) but a systematic bias between the two fat mass estimates was evident. To our knowledge there is no literature that discusses the accuracy of either iDXA or Prodigy fat mass measurement using the $4-\mathrm{C}$ model. However, previous literature has reported significant differences between fat mass (\%) measured by various DXA models (QDR2000, QDR2000W, DPX/L, and Lunar) and the 4-C model [25]. When comparing Prodigy and the 4$C$ model, Williams et al [25] found significant differences in fat mass (1.35, 1.21 and $1.58 \mathrm{~kg}$ in non-obese men, women and obese women, respectively). They also reported that the fat mass bias was positively associated with BMI. Although it appears that the accuracy of DXA has improved over the years, a systematic bias still remains between the iDXA and the 4-C model.

The differences identified between the two methods could have several origins. DXA assumes that the hydration value for fat-free mass remains constant [26], however this may 
not be true for participants across a range of masses. Participant mass itself may inflict a bias in soft tissue estimation because of the influence of tissue depth on bone edge detection by DXA, therefore as subject mass increases, so may the error in detecting soft tissue.

Comparisons between GE software versions (Basic and Enhanced) for Prodigy and a 4-C model have not been investigated before. There are many publications that demonstrate the transitions between instruments, but few that detail the differences when upgrading software versions. In the final part of this study we investigated the differences in whole body fat mass measurements between basic and enhanced software versions on the Prodigy and compared this to the iDXA and 4-C model.

Prodigy basic analysis mode compared to 4-C demonstrated a good agreement over a wide range of fat masses. However, in the highest fat masses the agreement was less good, consistent with previous studies [25, 27, 28]. As referred to earlier, Williams et al [25] reported the largest difference between 4-C and Prodigy (Encore 2002) in obese women (mean bias $1.58 \mathrm{~kg}$ ) and Wells et al [27] (Software version not stated), reported that Prodigy significantly over-estimated FM compared to $4-\mathrm{C}$ by $0.9 \mathrm{~kg}$ with the greatest variability being observed at the highest fat masses.

In summary, the latest DXA instrument from GE, the iDXA, comes with new hardware in the form of a more powerful X-ray tube, enhanced image resolution and therefore better bone edge detection. Furthermore the latest software, Encore version $15 \& 16$, comes with developed soft tissue algorithms. This enhancement in technology has led to an improvement in both accuracy and precision of the new instrument. However this means that differences exist between the iDXA and Prodigy instruments and therefore crosscalibration equations are essential if comparisons between instruments are unavoidable. Even with these improvements, accuracy issues remain at the highest fat masses, reinforcing the importance of deriving cross-calibration equations that are relevant to the population under investigation and also that further comparative studies are warranted in an obese population. 
333 The authors declare no conflict of interest

\section{Acknowledgements}

335 LPEW and PRM are supported by the NIHR/Wellcome Trust Clinical Research Facility

336 Cambridge. MCV is supported by the MRC Elsie Widdowson Laboratory (Programme

337 numbers: Physiological Modelling of Metabolic Risk, MC_UP_A090_1005, and Nutrition,

338 Surveys and Studies, MC_U105960384).

339 The authors would like to thank all of our participants without whom we could not have 340 completed this study. We would also like to thank: Katie Bird and Liz Blower at the

341 NIHR/Wellcome Trust Clinical Research Facility for their assistance with the DXA 342 measurements and dose administration and Priya Singh and Elise Orford at the Medical 343 Research Council (MRC) Elsie Widdowson Laboratory for their assistance in the deuterium 344 analysis. Of course we will remain forever indebted to Dr Les Bluck for all of his scientific 345 excellence and help in conceptualising the study and many other worthy contributions 346 before his untimely death.

\section{Author Contributions}

348 The authors responsibilities were as follows: LW - study concept and design, conducted 349 research, analysis and interpretation of data, drafted manuscript, and primary responsibility 350 for the final content, MV - critical revision of the manuscript and important intellectual contributions, PRM - critical revision of the manuscript and important intellectual contributions. All authors read and approved the final manuscript. 
354 1. Toombs, R.J., et al., The impact of recent technological advances on the trueness and precision of DXA to assess

body composition. Obesity (Silver Spring), 2012. 20(1): p. 30-9.

2. Hind, K., B. Oldroyd, and J.G. Truscott, In vivo precision of the GE Lunar iDXA densitometer for the measurement of total body composition and fat distribution in adults. Eur J Clin Nutr, 2011. 65(1): p. 140-2.

3. Hind, K., B. Oldroyd, and J.G. Truscott, In vivo precision of the GE Lunar iDXA densitometer for the measurement of total-body, lumbar spine, and femoral bone mineral density in adults. J Clin Densitom, 2010. 13(4): p. 413-7.

4. Shepherd, J.A., et al., Cross-calibration and minimum precision standards for dual-energy X-ray absorptiometry: the 2005 ISCD Official Positions. J Clin Densitom, 2006. 9(1): p. 31-6.

5. Baim, S., et al., Precision assessment and radiation safety for dual-energy X-ray absorptiometry: position paper of the International Society for Clinical Densitometry. J Clin Densitom, 2005. 8(4): p. 371-8.

6. Chen, X., N. Iqbal, and G. Boden, The effects of free fatty acids on gluconeogenesis and glycogenolysis in normal subjects. J Clin Invest, 1999. 103(3): p. 365-72.

7. Fuller, N.J., et al., Four-component model for the assessment of body composition in humans: comparison with alternative methods, and evaluation of the density and hydration of fat-free mass. Clin Sci (Lond), 1992. 82(6): $p$. 687-93.

8. IAEA, Assessment of Body Composition and Total Energy Expenditure in Humans Using Stable Isotope Techniques, in IAEA Human Health Series. 2009: Vienna. p. 146.

9. Coward, W.A., Measurement of energy expenditure: the doubly-labelled-water method in clinical practice. Proc Nutr Soc, 1991. 50(2): p. 227-37.

10. Schoeller, D.A. and J.M. Hnilicka, Reliability of the doubly labeled water method for the measurement of total daily energy expenditure in free-living subjects. J Nutr, 1996. 126(1): p. 348S-354S.

11. Rothney, M.P., et al., Precision of GE Lunar iDXA for the measurement of total and regional body composition in nonobese adults. J Clin Densitom, 2012. 15(4): p. 399-404.

12. Kaminsky, L.A., et al., Precision of total and regional body fat estimates from dual-energy X-ray absorptiometer measurements. J Nutr Health Aging, 2014. 18(6): p. 591-4.

13. Knapp, K.M., et al., Obesity increases precision errors in total body dual-energy $x$-ray absorptiometry measurements. J Clin Densitom, 2015. 18(2): p. 209-16.

14. Oldroyd, B., A.H. Smith, and J.G. Truscott, Cross-calibration of GE/Lunar pencil and fan-beam dual energy densitometers--bone mineral density and body composition studies. Eur J Clin Nutr, 2003. 57(8): p. 977-87.

15. Krueger, D., et al., BMD measurement and precision: a comparison of GE Lunar Prodigy and iDXA densitometers. J Clin Densitom, 2012. 15(1): p. 21-5.

16. Bilsborough, J.C., et al., The accuracy and precision of DXA for assessing body composition in team sport athletes. J Sports Sci, 2014. 32(19): p. 1821-8.

17. Healthcare, G., Lunar iDXA: Intelligent DXA, G. Healthcare, Editor. 2006: Belgium. p. 10.

18. Hind, K., et al., A cross-calibration study of the GE-Lunar iDXA and prodigy for the assessment of lumbar spine and total hip bone parameters via three statistical methods. J Clin Densitom, 2015. 18(1): p. 86-92.

19. Hull, H., et al., iDXA, Prodigy, and DPXL dual-energy X-ray absorptiometry whole-body scans: a cross-calibration study. J Clin Densitom, 2009. 12(1): p. 95-102.

20. Rhodes, L.A., et al., Cross-calibration of a GE iDXA and Prodigy for total and regional body bone parameters: the importance of using cross-calibration equations for longitudinal monitoring after a system upgrade. J Clin Densitom, 2014. 17(4): p. 496-504.

21. Morrison, S.A., et al., Comparison of the Lunar Prodigy and iDXA Dual-Energy X-ray Absorptiometers for Assessing Total and Regional Body Composition. J Clin Densitom, 2016. 19(3): p. 290-7.

22. Lohman, T.G., et al., Assessing body composition and changes in body composition. Another look at dual-energy $X$-ray absorptiometry. Ann N Y Acad Sci, 2000. 904: p. 45-54.

23. Muller, M.J., et al., Application of standards and models in body composition analysis. Proc Nutr Soc, 2016. 75(2): p. 181-7.

24. Heymsfield, S.B., et al., Multi-component molecular-level body composition reference methods: evolving concepts and future directions. Obes Rev, 2015. 16(4): p. 282-94.

25. Williams, J.E., et al., Evaluation of Lunar Prodigy dual-energy X-ray absorptiometry for assessing body composition in healthy persons and patients by comparison with the criterion 4-component model. Am J Clin Nutr, 2006. 83(5): p. 1047-54.

26. Wang, Z., et al., Hydration of fat-free body mass: review and critique of a classic body-composition constant. Am J Clin Nutr, 1999. 69(5): p. 833-41.

27. Wells, J.C., et al., Body-composition reference data for simple and reference techniques and a 4-component model: a new UK reference child. Am J Clin Nutr, 2012. 96(6): p. 1316-26.

28. Wells, J.C., et al., Body composition in young female eating-disorder patients with severe weight loss and controls: evidence from the four-component model and evaluation of DXA. Eur J Clin Nutr, 2015. 69(12): p. 1330-5. 


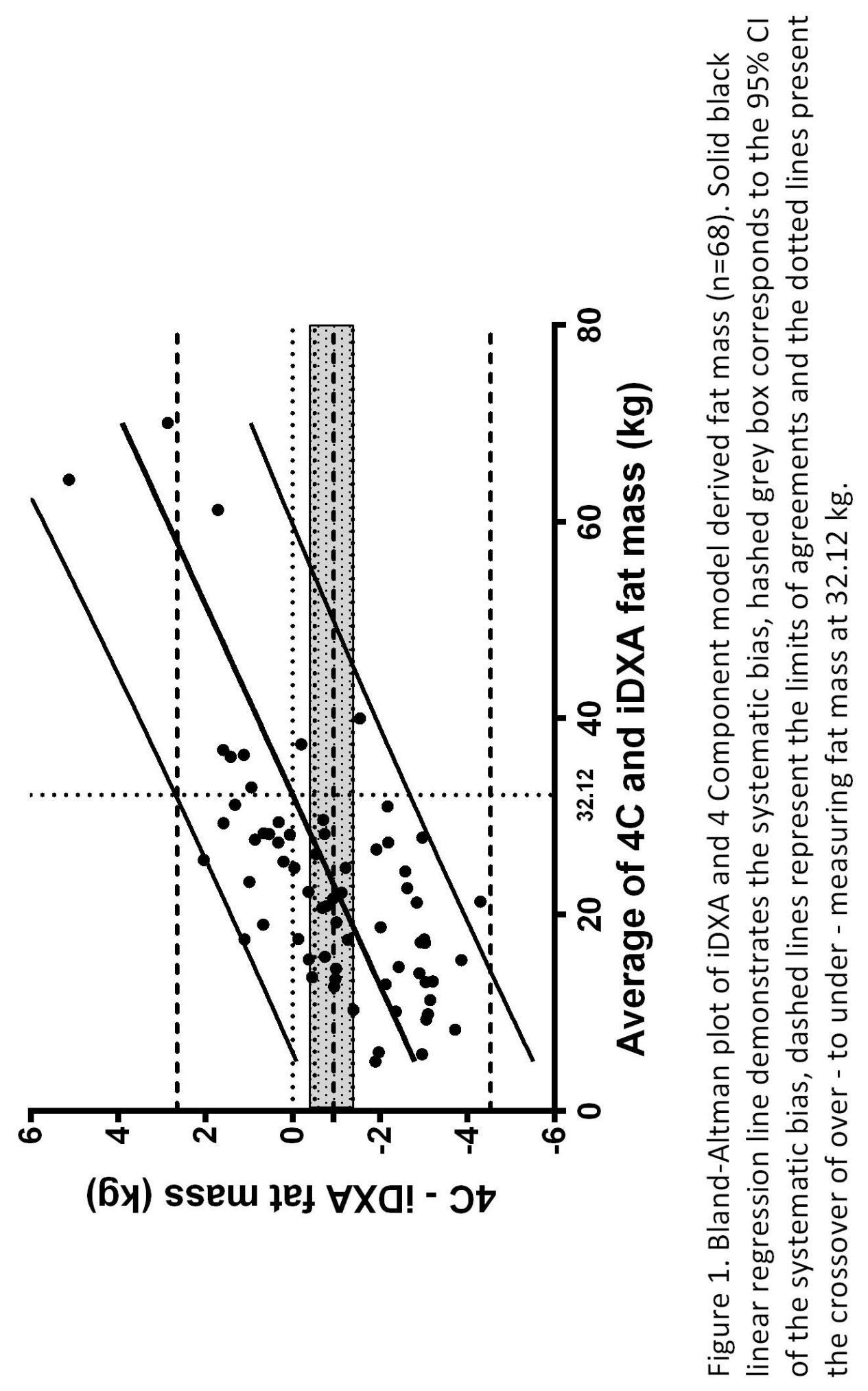




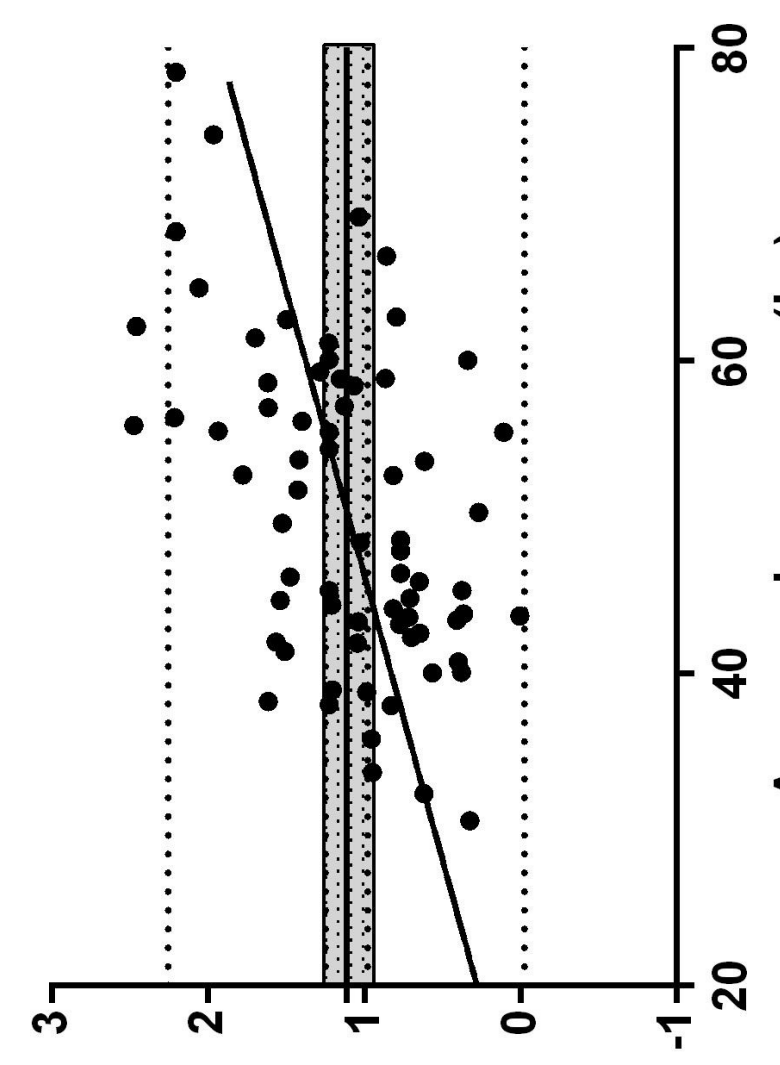

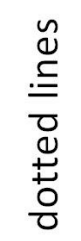

음

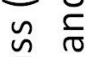

है vi

등

$\stackrel{0}{9}$.

동

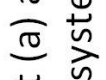

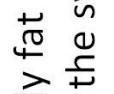

중늠

능

은 ํำ

원

जे 웅

$\stackrel{0}{0}$

$\varepsilon$ ᄃ

흐음

흔 닌

웜

당

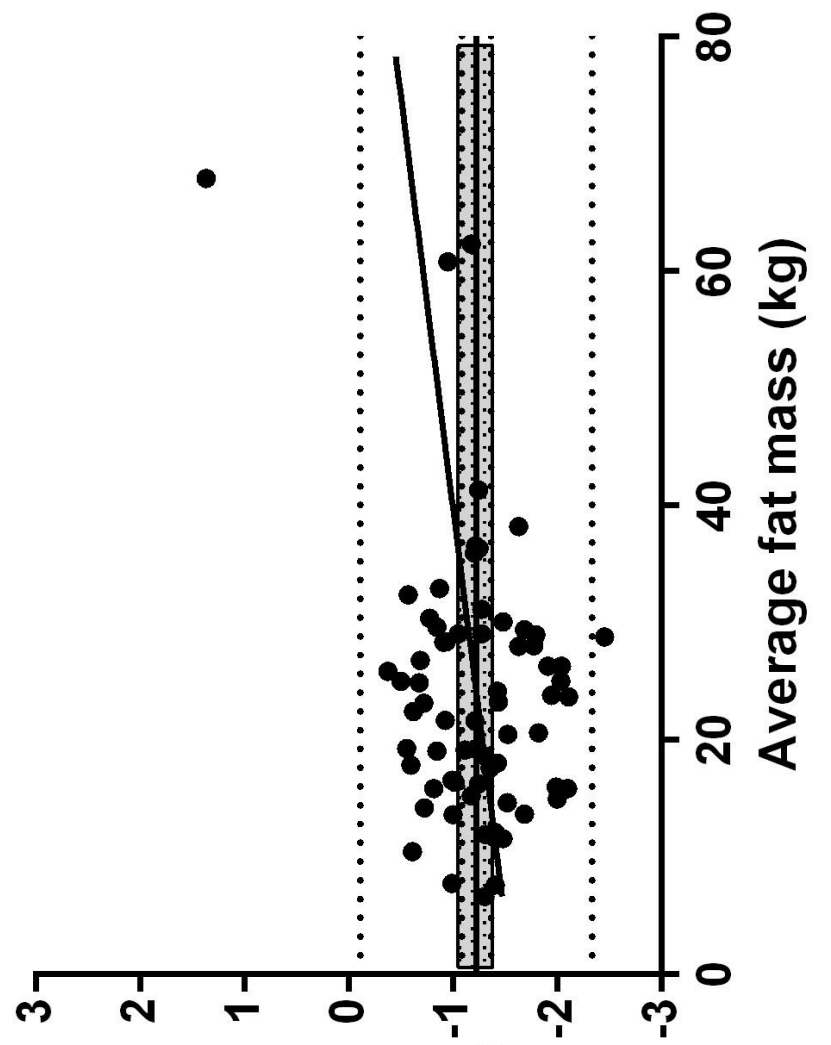

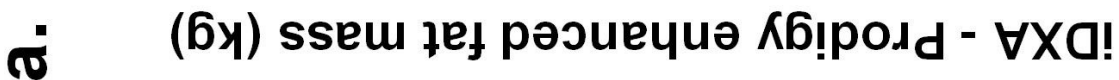

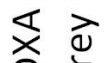

으

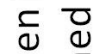

$\sum_{\substack{0 \\ 0}}^{\infty} \frac{2}{\infty}$

ป

产 $\frac{\pi}{0}$

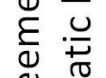

ब

क्ष

0

满

$\frac{n}{N}+\frac{0}{2}$

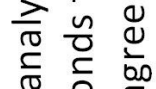

ᄃ

든

这 号:

등

๑ 늠

궁

늑음 음 


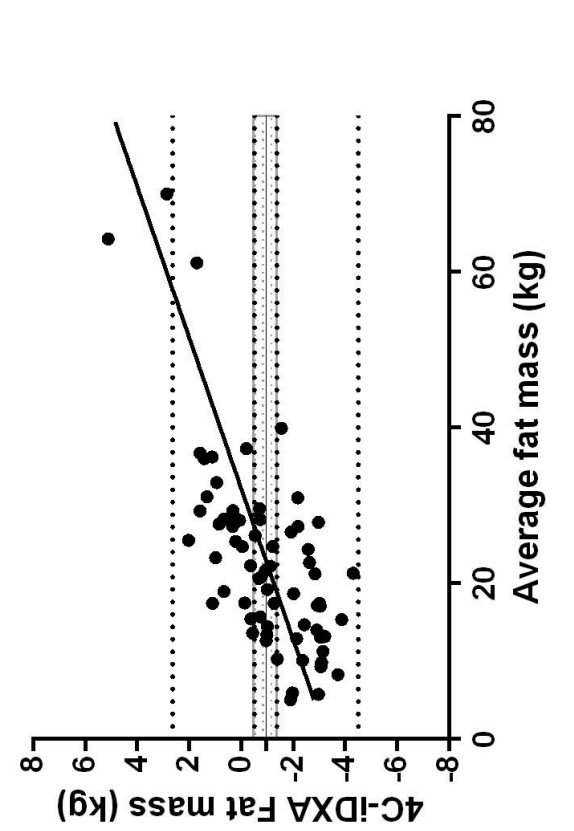

0

늠

这

商

든.

를

प्ष

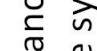

孚

山ั

은

응 ㅇำ

음

त)

$\frac{n}{n} 0$

(6y) ssem le $\forall \forall X a !-0 t$ त

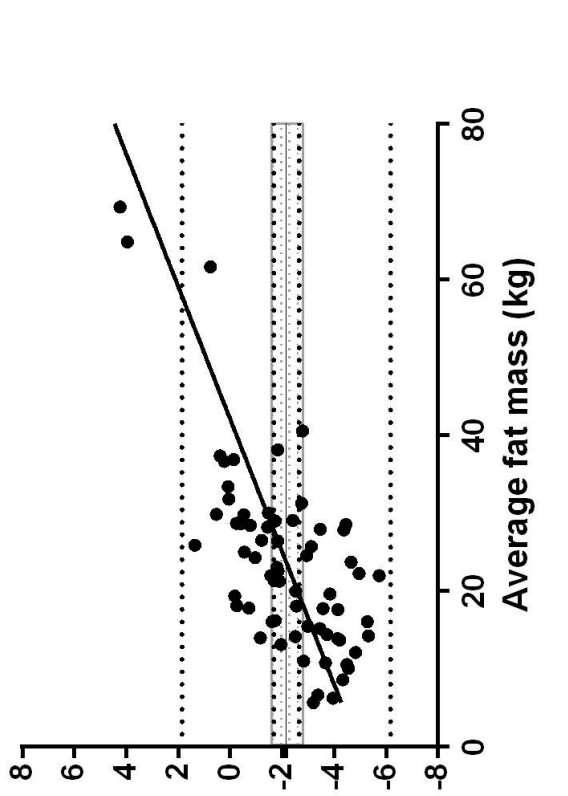

$\begin{array}{cc}\frac{1}{\pi} & \frac{1}{0} \\ \frac{u}{n} & \frac{0}{n} \\ \pi & 0 \\ 0 & \frac{1}{2}\end{array}$

㐅ิ

흐응

ํํㅇ

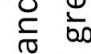

ब

돈

芹桴

$\div \frac{0}{0}$

을

ป

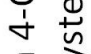

वे के

¿

要

ㅇ

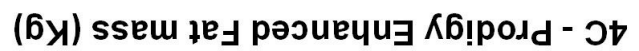

은

ปั ฝิ

인 닌

훙

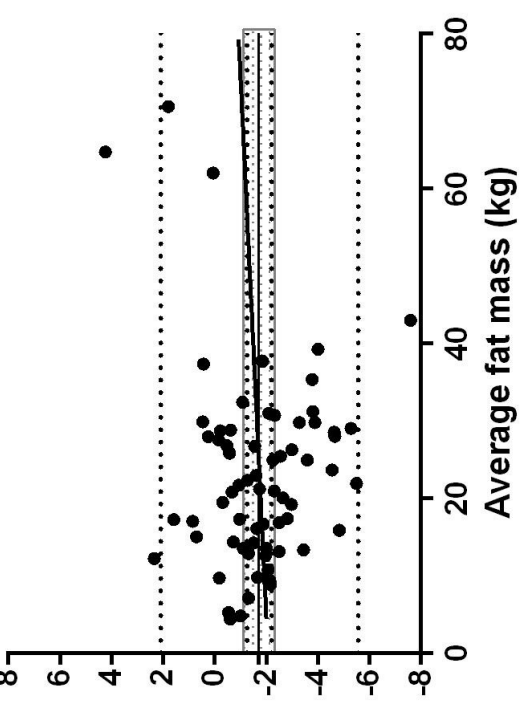

ত

\&

Чั

๘

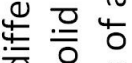

章

पे

ᄂ

동 Ð

당

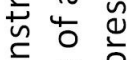

은 는

बे

$\circ$ 을

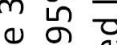

웡

(Б) 


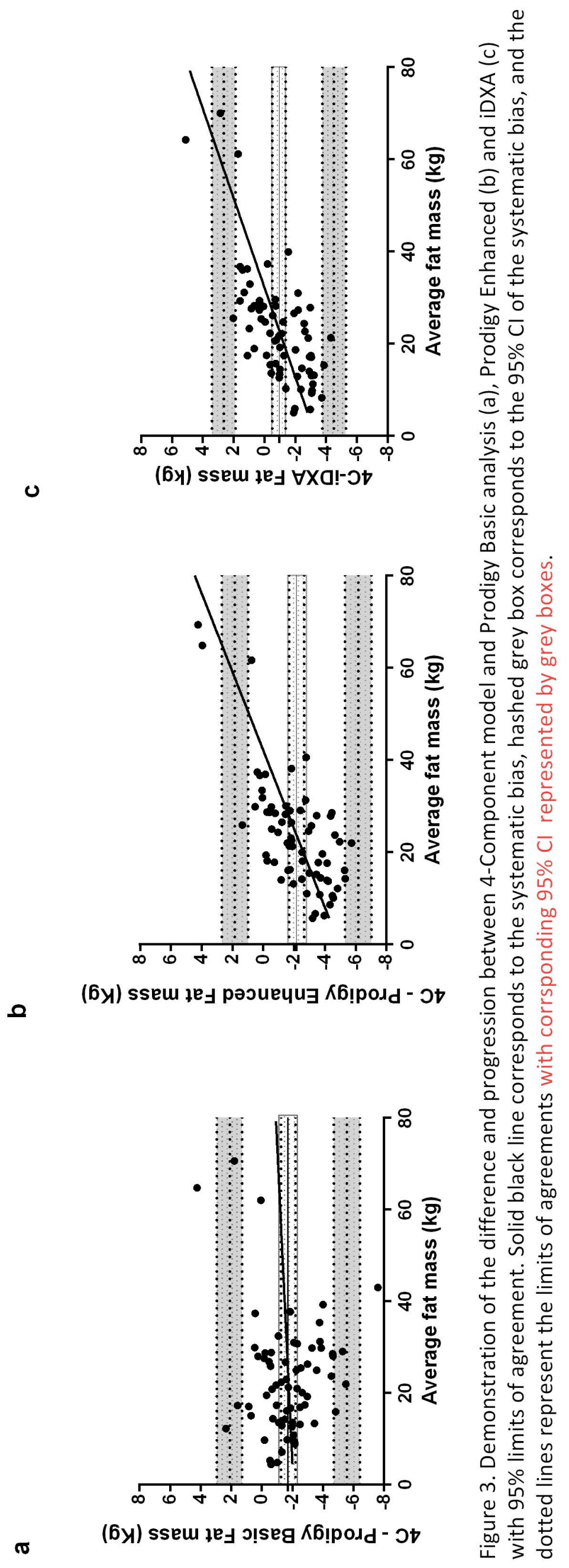


Table 1. Descriptive data of the participants

\begin{tabular}{ccc}
\hline & Mean \pm SD & Range \\
\hline \hline Age (years) & $37.7 \pm 12.3$ & $19.2-64.1$ \\
Height $(\mathrm{m})$ & $1.73 \pm 9.9$ & $1.53-2.01$ \\
Mass $(\mathrm{kg})^{1}$ & $77.3 \pm 15.8$ & $49.1-129.6$ \\
BMI (kg/m²) & $26.2 \pm 5.2$ & $18.4-47.5$ \\
Fat mass $(\mathrm{kg})(4-\mathrm{C})$ & $22.3 \pm 13.0$ & $3.7-70.7$ \\
\% Fat (4-C) & $28.0 \pm 12.0$ & $5.3-54.5$
\end{tabular}

SD; standard deviation, BMI; Body mass index, 4-C; 4 Component model $(n=68)$. Hip analysis $\mathrm{n}=67$. Scan mode: Standard $\mathrm{n}=65$, thick $\mathrm{n}=4 .{ }^{1}$ ADP mass (mean difference \pm SD in mass $(\mathrm{kg}$ ) between ADP and iDXA; $0.15 \pm 0.50$, and Prodigy; $-0.02 \pm 0.65$ ). 
Table 2. Precision variables of two iDXA whole-body and regional body composition measurements.

\begin{tabular}{|c|c|c|c|c|c|c|}
\hline Region & Variables & Mean \pm SD & $\begin{array}{c}\text { Mean } \\
\text { Difference }\end{array}$ & RMS-SD & CV (\%) & LSC \\
\hline \multirow[t]{3}{*}{ Hip } & $\mathrm{BMC}(\mathrm{g})$ & $35.98 \pm 7.61$ & -0.07 & 0.46 & 1.05 & 1.29 \\
\hline & Area $\left(\mathrm{cm}^{2}\right)$ & $33.21 \pm 3.98$ & 0.06 & 0.28 & 0.59 & 0.77 \\
\hline & $\mathrm{BMD}\left(\mathrm{g} / \mathrm{cm}^{2}\right)$ & $1.08 \pm 0.16$ & -0.00 & 0.01 & 0.72 & 0.03 \\
\hline \multirow[t]{3}{*}{ Spine } & $\mathrm{BMC}(\mathrm{g})$ & $58.74 \pm 12.09$ & -0.44 & 0.71 & 0.86 & 1.96 \\
\hline & Area $\left(\mathrm{cm}^{2}\right)$ & $46.59 \pm 5.61$ & 0.02 & 0.42 & 0.54 & 1.16 \\
\hline & $\mathrm{BMD}\left(\mathrm{g} / \mathrm{cm}^{2}\right)$ & $1.25 \pm 0.15$ & -0.01 & 0.01 & 0.74 & 0.04 \\
\hline Whole Body & $\mathrm{BMC}(\mathrm{kg})$ & $2.82 \pm 0.58$ & -0.00 & 0.02 & 0.44 & 0.04 \\
\hline \multirow[t]{2}{*}{ Arms } & Fat mass (kg) & $2.26 \pm 1.11$ & -0.01 & 0.06 & 2.28 & 0.16 \\
\hline & Lean mass $(\mathrm{kg})$ & $5.61 \pm 1.78$ & 0.01 & 0.09 & 1.20 & 0.25 \\
\hline \multirow[t]{2}{*}{ Legs } & Fat mass (kg) & $8.38 \pm 4.45$ & -0.05 & 0.18 & 1.32 & 0.50 \\
\hline & Lean mass $(\mathrm{kg})$ & $18.24 \pm 4.00$ & -0.07 & 0.19 & 0.74 & 0.52 \\
\hline \multirow[t]{2}{*}{ Trunk } & Fat mass (kg) & $6.12 \pm 6.49$ & -0.00 & 0.26 & 1.58 & 0.72 \\
\hline & Lean mass $(\mathrm{kg})$ & $24.03 \pm 4.64$ & 0.11 & 0.29 & 0.93 & 0.80 \\
\hline \multirow[t]{2}{*}{ Whole Body } & Fat mass (kg) & $23.57 \pm 11.51$ & -0.07 & 0.27 & 0.86 & 0.65 \\
\hline & Lean mass $(\mathrm{kg})$ & $51.00 \pm 10.39$ & 0.07 & 0.28 & 0.42 & 0.78 \\
\hline
\end{tabular}

RMS-SD, root mean square standard deviation; \%CV, percent coefficient of variance; LSC, ideal least significant change. 
Table 3. Whole body and regional iDXA and Prodigy enhanced bone density measurements.

\begin{tabular}{llcccc}
\hline Region & Variables & iDXA & Prodigy Enhanced & Bias & LOA \\
\hline Whole Body & BMC $(\mathrm{kg})$ & $2.82 \pm 0.59$ & $2.80 \pm 0.58$ & $0.02 \pm 0.05^{*}$ & $-0.07-0.12$ \\
& Area $\left(\mathrm{cm}^{2}\right)$ & $2255 \pm 234.3$ & $2219 \pm 236.9$ & $35.8 \pm 51.0^{*}$ & $-64.2-135.7$ \\
& BMD $\left(\mathrm{g} / \mathrm{cm}^{2}\right)$ & $1.24 \pm 0.15$ & $1.25 \pm 0.16$ & $-0.01 \pm 0.02^{*}$ & $-0.06-0.04$ \\
Hip & BMC $(\mathrm{g})$ & $36.0 \pm 7.6$ & $36.01 \pm 7.6$ & $-0.07 \pm 1.148$ & $-2.32-2.18$ \\
& Area $\left(\mathrm{cm}^{2}\right)$ & $33.2 \pm 4.0$ & $33.2 \pm 3.9$ & $0.06 \pm 0.87$ & $-1.64-1.76$ \\
\multirow{3}{*}{ Spine } & BMD $\left(\mathrm{g} / \mathrm{cm}^{2}\right)$ & $1.08 \pm 0.16$ & $1.08 \pm 0.15$ & $-0.00 \pm 0.02$ & $-0.04-0.04$ \\
& BMC $(\mathrm{g})$ & $58.7 \pm 12.1$ & $59.2 \pm 12.3$ & $-0.44 \pm 1.21^{*}$ & $-2.82-1.93$ \\
& Area $\left(\mathrm{cm}^{2}\right)$ & $46.6 \pm 5.6$ & $46.6 \pm 5.61$ & $0.02 \pm 0.76$ & $-1.48-1.51$ \\
& BMD $\left(\mathrm{g} / \mathrm{cm}^{2}\right)$ & $1.25 \pm 0.15$ & $1.26 \pm 0.15$ & $-0.01 \pm 0.02 *$ & $-0.05-0.04$ \\
\hline
\end{tabular}

Mean \pm standard deviation. ${ }^{*} P<0.05$. BMC, bone mineral content; $\mathrm{BMD}$, bone mineral density. 
Table 4. Whole body and regional iDXA and Prodigy enhanced body composition measurements.

\begin{tabular}{llcccc}
\hline Region & Variables & iDXA & $\begin{array}{c}\text { Prodigy } \\
\text { enhanced }\end{array}$ & Bias & LOA \\
\hline Whole body & Fat mass $(\mathrm{kg})$ & $23.59 \pm 11.64$ & $24.88 \pm 11.74$ & $-1.29 \pm 0.56^{*}$ & $-2.53-0.05$ \\
& Lean mass $(\mathrm{kg})$ & $51.00 \pm 10.42$ & $49.88 \pm 10.14$ & $1.18 \pm 0.57^{*}$ & $0.00-2.24$ \\
\multirow{2}{*}{ Arm } & Fat mass (kg) & $2.26 \pm 1.12$ & $2.51 \pm 1.15$ & $-0.25 \pm 0.19^{*}$ & $-0.62-0.12$ \\
& Lean mass (kg) & $5.61 \pm 1.78$ & $5.41 \pm 1.80$ & $0.20 \pm 0.33^{*}$ & $-0.46-0.85$ \\
Leg & Fat mass (kg) & $8.38 \pm 4.47$ & $8.93 \pm 4.51$ & $-0.54 \pm 0.30^{*}$ & $-1.13-0.05$ \\
& Lean mass (kg) & $18.24 \pm 4.02$ & $17.79 \pm 3.87$ & $0.46 \pm 0.63^{*}$ & $-0.77-1.68$ \\
Trunk & Fat mass (kg) & $12.12 \pm 6.51$ & $12.58 \pm 6.43$ & $-0.46 \pm 0.42^{*}$ & $-1.28-0.35$ \\
& Lean mass (kg) & $24.03 \pm 4.65$ & $23.63 \pm 4.41$ & $0.41 \pm 0.72^{*}$ & $-1.00-1.81$ \\
\hline
\end{tabular}

Mean \pm standard deviation, ${ }^{*} \mathrm{P}<0.05$ 
Table 5. Cross-calibration equations (Prodigy enhanced to iDXA).

\begin{tabular}{|c|c|c|c|c|c|c|}
\hline & Variable & Slope & $95 \% \mathrm{Cl}$ & Intercept & $95 \% \mathrm{Cl}$ & $r^{2}$ \\
\hline \multirow{5}{*}{ Whole body } & $\mathrm{BMC}(\mathrm{g})$ & $1.003^{*}$ & $0.983-1.023$ & 0.017 & $-0.041-0.074$ & 0.993 \\
\hline & $\mathrm{BA}\left(\mathrm{cm}^{2}\right)$ & $0.966^{*}$ & $0.914-1.017$ & 112.0 & $-3.543-227.6$ & 0.953 \\
\hline & $\mathrm{BMD}\left(\mathrm{g} / \mathrm{cm}^{2}\right)$ & $0.965^{*}$ & $0.928-1.001$ & 0.035 & $-0.011-0.081$ & 0.976 \\
\hline & Fat mass (kg) & $0.991^{*}$ & $0.978-1.005$ & $-1.016^{*}$ & $-1.393--0.639$ & 0.997 \\
\hline & Lean mass (kg) & 1.029 & $1.013-1.045$ & -0.262 & $-1.058-0.535$ & 0.996 \\
\hline \multirow[t]{3}{*}{ Spine } & $\mathrm{BMC}(\mathrm{g})$ & $0.978^{*}$ & $0.954-1.001$ & 0.877 & $-0.537-2.290$ & 0.990 \\
\hline & $\mathrm{BA}\left(\mathrm{cm}^{2}\right)$ & $0.990^{*}$ & $0.956-1.023$ & 0.505 & $-1.045-2.055$ & 0.981 \\
\hline & $\mathrm{BMD}\left(\mathrm{g} / \mathrm{cm}^{2}\right)$ & 0.986 & $0.950-1.022$ & 0.008 & $-0.038-0.054$ & 0.978 \\
\hline \multirow[t]{6}{*}{ Regional } & Arm fat mass (kg) & $0.962^{*}$ & $0.923-1.001$ & $-0.155^{*}$ & $-0.262--0.048$ & 0.973 \\
\hline & Arm lean mass (kg) & $0.972^{*}$ & $0.927-1.016$ & $0.350^{*}$ & $0.097-0.603$ & 0.966 \\
\hline & Leg Fat mass (kg) & $0.989^{*}$ & $0.973-1.005$ & $-0.444^{*}$ & $-0.604--0.284$ & 0.996 \\
\hline & Leg Lean mass (kg) & $1.024^{*}$ & $0.985-1.063$ & 0.036 & $-0.673-0.746$ & 0.976 \\
\hline & Trunk Fat mass (kg) & $1.010^{*}$ & $0.995-1.026$ & $-0.591^{*}$ & $-0.811--0.372$ & 0.996 \\
\hline & Trunk Lean mass (kg) & $1.042^{*}$ & $1.003-1.080$ & -0.576 & $-1.494-0.341$ & 0.978 \\
\hline
\end{tabular}

$\mathrm{Cl}$, Confidence intervals; Adjusted $\mathrm{r}^{2}$, model variance, ${ }^{*} \mathrm{P}<0.05$. 
Supplementary Table 1. Difference between iDXA enhanced and Prodigy basic software analysis: whole-body and regional bone mass, area and density measurements

\begin{tabular}{llccc}
\hline Region & Variables & iDXA & Prodigy & Difference \\
\hline $\begin{array}{l}\text { Total } \\
\text { Body }\end{array}$ & BMC $(\mathrm{kg})$ & $2.82 \pm 0.59$ & $3.02 \pm 0.65$ & $-0.20 \pm 0.14^{*}$ \\
& BA $\left(\mathrm{cm}^{2}\right)$ & $2.26 \pm 0.23$ & $2.40 \pm 0.31$ & $-0.14 \pm 0.16^{*}$ \\
& BMD $\left(\mathrm{kg} / \mathrm{cm}^{2}\right)$ & $1.24 \pm 0.15$ & $1.25 \pm 0.13$ & $-0.01 \pm 0.04^{*}$ \\
Hip & BMC $(\mathrm{g})$ & $35.98 \pm 7.62$ & $36.05 \pm 7.57$ & $-0.06 \pm 1.15$ \\
& BA $\left(\mathrm{cm}^{2}\right)$ & $33.21 \pm 3.98$ & $33.15 \pm 3.92$ & $0.06 \pm 0.87$ \\
& BMD $\left(\mathrm{g} / \mathrm{cm}^{2}\right)$ & $1.08 \pm 0.16$ & $1.08 \pm 0.15$ & $0.00 \pm 0.02$ \\
Spine & BMC $(\mathrm{g})$ & $58.74 \pm 12.09$ & $59.18 \pm 12.31$ & $-0.44 \pm 1.21^{*}$ \\
& BA $\left(\mathrm{cm}^{2}\right)$ & $46.59 \pm 5.61$ & $46.57 \pm 5.61$ & $0.02 \pm 0.76$ \\
& BMD $\left(\mathrm{g} / \mathrm{cm}^{2}\right)$ & $1.25 \pm 0.15$ & $1.26 \pm 0.15$ & $-0.01 \pm 0.02^{*}$ \\
\hline
\end{tabular}

Means \pm Standard Deviations * $\mathrm{P}<0.05$ 
Supplementary Table 2. Difference between iDXA enhanced and Prodigy basic software analysis: whole-body and regional body composition measurements

\begin{tabular}{llccc}
\hline Region & Variables & iDXA & Prodigy & Difference \\
\hline Whole body & Fat mass $(\mathrm{kg})$ & $23.59 \pm 11.64$ & $25.97 \pm 14.44$ & $-0.79 \pm 1.73^{*}$ \\
& Lean mass $(\mathrm{kg})$ & $51.00 \pm 10.42$ & $49.82 \pm 10.90$ & $1.18 \pm 1.99^{*}$ \\
\multirow{2}{*}{ Arm } & Fat mass $(\mathrm{kg})$ & $2.26 \pm 1.12$ & $2.10 \pm 12.72$ & $-0.16 \pm 0.21^{* *}$ \\
& Lean mass $(\mathrm{kg})$ & $5.61 \pm 1.78$ & $5.43 \pm 1.82$ & $0.17 \pm 0.23^{* *}$ \\
Leg & Fat mass $(\mathrm{kg})$ & $8.38 \pm 4.47$ & $8.82 \pm 5.04$ & $-0.44 \pm 0.71^{* *}$ \\
& Lean mass $(\mathrm{kg})$ & $18.24 \pm 4.02$ & $17.39 \pm 4.07$ & $0.85 \pm 0.89^{* *}$ \\
Trunk & Fat mass $(\mathrm{kg})$ & $12.12 \pm 6.51$ & $12.79 \pm 6.66$ & $-0.67 \pm 1.11^{* *}$ \\
& Lean mass $(\mathrm{kg})$ & $24.03 \pm 4.65$ & $23.74 \pm 4.88$ & $0.29 \pm 1.24$ \\
\hline
\end{tabular}


Supplementary Table 3. Cross calibration equations relating Prodigy data collected and analysed using Encore basic software versions to iDXA enhanced analysis.

\begin{tabular}{|c|c|c|c|c|c|c|}
\hline & Variable & Slope & $95 \% \mathrm{Cl}$ & Intercept & $95 \% \mathrm{Cl}$ & $r^{2}$ \\
\hline \multirow[t]{5}{*}{ Whole body } & $\mathrm{BMC}(\mathrm{kg})$ & 0.886 & $0.841-0.931$ & 0.147 & $0.007-0.286$ & 0.957 \\
\hline & $\mathrm{BA}\left(\mathrm{cm}^{2}\right)$ & 0.661 & $0.570-0.751$ & 0.672 & $0.452-0.891$ & 0.760 \\
\hline & BMD (kg/cm²) & 1.199 & $1.146-1.252$ & -0.254 & $-0.320--0.187$ & 0.968 \\
\hline & Fat mass (kg) & 0.909 & $0.885-0.934$ & 1.416 & $0.740-2.093$ & 0.988 \\
\hline & Lean mass (kg) & 0.941 & $0.899-0.983$ & 4.117 & $1.969-6.265$ & 0.967 \\
\hline \multirow[t]{8}{*}{ Regional } & Spine BMC (g) & 0.978 & $0.954-1.001$ & 0.877 & $-0.537-2.290$ & 0.990 \\
\hline & Spine BA $\left(\mathrm{cm}^{2}\right)$ & 0.990 & $0.956-1.023$ & 0.504 & $-1.046-2.055$ & 0.982 \\
\hline & Spine BMD $\left(\mathrm{g} / \mathrm{cm}^{2}\right)$ & 0.986 & $0.950-1.022$ & 0.008 & $-0.038-0.054$ & 0.978 \\
\hline & Arm fat mass (kg) & 0.874 & $0.847-0.902$ & 0.421 & $0.354-0.489$ & 0.983 \\
\hline & Arm lean mass (kg) & 0.973 & $0.943-1.004$ & 0.317 & $0.141-0.493$ & 0.984 \\
\hline & Leg Fat mass (kg) & 0.882 & $0.864-0.901$ & 0.599 & $0.407-0.791$ & 0.992 \\
\hline & Leg Lean mass (kg) & 0.963 & 0.910-1.015 & 1.500 & $0.565-2.434$ & 0.953 \\
\hline & Trunk Fat mass (kg) & 0.963 & $0.923-1.003$ & -0.201 & $-0.733-0.370$ & 0.972 \\
\hline
\end{tabular}

$\mathrm{Cl}$, Confidence intervals; adjusted $\mathrm{r}^{2}$, model variance. 
Supplementary Table 1. Difference between iDXA enhanced and Prodigy basic software analysis: whole-body and regional bone mass, area and density measurements

\begin{tabular}{llccc}
\hline Region & Variables & iDXA & Prodigy & Difference \\
\hline $\begin{array}{l}\text { Total } \\
\text { Body }\end{array}$ & BMC $(\mathrm{kg})$ & $2.8 \pm 0.6$ & $3.0 \pm 0.7$ & $-0.2 \pm 0.1^{*}$ \\
& BA $\left(\mathrm{cm}^{2}\right)$ & $2255.1 \pm 234.3$ & $2397.9 \pm 308.7$ & $-0.1 \pm 0.2^{*}$ \\
& BMD $\left(\mathrm{kg} / \mathrm{cm}^{2}\right)$ & $1.24 \pm 0.15$ & $1.25 \pm 0.13$ & $-0.01 \pm 0.04^{*}$ \\
Hip & BMC $(\mathrm{g})$ & $36.0 \pm 7.6$ & $36.1 \pm 7.6$ & $-0.1 \pm 1.2$ \\
& BA $\left(\mathrm{cm}^{2}\right)$ & $33.2 \pm 4.0$ & $33.2 \pm 3.9$ & $0.1 \pm 0.9$ \\
& BMD $\left(\mathrm{g} / \mathrm{cm}^{2}\right)$ & $1.08 \pm 0.16$ & $1.08 \pm 0.15$ & $0.00 \pm 0.02$ \\
Spine & BMC $(\mathrm{g})$ & $59.1 \pm 12.1$ & $59.2 \pm 12.3$ & $-0.4 \pm 1.2^{*}$ \\
& BA $\left(\mathrm{cm}^{2}\right)$ & $46.6 \pm 5.6$ & $46.6 \pm 5.6$ & $0.0 \pm 0.8$ \\
& BMD $\left(\mathrm{g} / \mathrm{cm}^{2}\right)$ & $1.25 \pm 0.15$ & $1.26 \pm 0.15$ & $-0.01 \pm 0.02^{*}$ \\
\hline
\end{tabular}

Mean \pm Standard Deviation ${ }^{*} \mathrm{P}<0.05$ 
Supplementary Table 2. Difference between iDXA enhanced and Prodigy basic software analysis: whole-body and regional body composition measurements

\begin{tabular}{llccc}
\hline Region & Variables & iDXA & Prodigy & Difference \\
\hline Whole body & Fat mass $(\mathrm{kg})$ & $23.6 \pm 11.6$ & $24.4 \pm 12.7$ & $-0.8 \pm 1.7^{*}$ \\
& Lean mass $(\mathrm{kg})$ & $51.0 \pm 10.4$ & $49.9 \pm 10.9$ & $1.2 \pm 2.0^{*}$ \\
\multirow{2}{*}{ Arm } & Fat mass $(\mathrm{kg})$ & $2.3 \pm 1.1$ & $2.1 \pm 12.7$ & $-0.2 \pm 0.2^{*}$ \\
& Lean mass $(\mathrm{kg})$ & $5.6 \pm 1.8$ & $5.4 \pm 1.8$ & $0.2 \pm 0.2^{*}$ \\
Leg & Fat mass $(\mathrm{kg})$ & $8.4 \pm 4.5$ & $8.8 \pm 5.0$ & $-0.4 \pm 0.7^{*}$ \\
& Lean mass $(\mathrm{kg})$ & $18.2 \pm 4.0$ & $17.4 \pm 4.1$ & $0.9 \pm 0.9^{*}$ \\
Trunk & Fat mass $(\mathrm{kg})$ & $12.1 \pm 6.5$ & $12.8 \pm 6.7$ & $-0.7 \pm 1.1^{*}$ \\
& Lean mass $(\mathrm{kg})$ & $24.0 \pm 4.7$ & $23.7 \pm 4.9$ & $0.3 \pm 1.2$ \\
\hline
\end{tabular}

Mean \pm Standard Deviation ${ }^{*} \mathrm{P}<0.05$ 
Table 1. Descriptive data of the participants

\begin{tabular}{ccccc}
\hline \multicolumn{3}{c}{ Males $\mathrm{n}=33$} & \multicolumn{3}{l}{ Females $\mathrm{n}=36$} \\
\hline \hline & Mean \pm SD & Range & Mean \pm SD & Range \\
\hline \hline Age (years) & $38.0 \pm 12.0$ & $19.9-65.1$ & $37.8 \pm 12.7$ & $19.2-57.9$ \\
Height (m) & $1.80 \pm 0.08$ & $1.62-2.01$ & $1.66 \pm 6.7$ & $1.53-1.83$ \\
Mass (kg) & $81.0 \pm 12.0$ & $54.1-106.9$ & $73.9 \pm 18.1$ & $49.1-129.6$ \\
BMI (kg/m²) & $25.3 \pm 3.2$ & $20.2-34.2$ & $27.0 \pm 6.3$ & $18.4-47.5$ \\
Fat mass (kg) (4-C) & $16.8 \pm 8.1$ & $4.1-33.4$ & $28.0 \pm 14.4$ & $9.57-71.5$ \\
\% Fat (4-C) & $20.1 \pm 8.0$ & $5.3-34.4$ & $36.0 \pm 9.5$ & $18.5-55.1$
\end{tabular}

$\overline{\text { SD; standard deviation, BMI; Body mass index, 4-C; } 4 \text { Component model }(n=68) \text {. Hip }}$ analysis $\mathrm{n}=67$. Scan mode: Standard $\mathrm{n}=65$, thick $\mathrm{n}=4 .{ }^{1}$ ADP mass. 
Table 2. Precision variables of two iDXA whole-body and regional body composition measurements.

\begin{tabular}{|c|c|c|c|c|c|c|}
\hline Region & Variables & Mean \pm SD & $\begin{array}{c}\text { Mean } \\
\text { Difference }\end{array}$ & RMS-SD & CV (\%) & LSC \\
\hline \multirow[t]{3}{*}{ Hip } & $\mathrm{BMC}(\mathrm{g})$ & $36.0 \pm 7.6$ & -0.1 & 0.5 & 1.1 & 1.3 \\
\hline & Area $\left(\mathrm{cm}^{2}\right)$ & $33.2 \pm 4.0$ & 0.4 & 0.3 & 0.6 & 0.8 \\
\hline & $\mathrm{BMD}\left(\mathrm{g} / \mathrm{cm}^{2}\right)$ & $1.08 \pm 0.16$ & 0.00 & 0.01 & 0.72 & 0.03 \\
\hline \multirow[t]{3}{*}{ Spine } & $\mathrm{BMC}(\mathrm{g})$ & $58.7 \pm 12.1$ & -0.4 & 0.7 & 0.9 & 2.0 \\
\hline & Area $\left(\mathrm{cm}^{2}\right)$ & $46.6 \pm 0.3$ & 0.0 & 0.4 & 0.5 & 1.2 \\
\hline & $\mathrm{BMD}\left(\mathrm{g} / \mathrm{cm}^{2}\right)$ & $1.25 \pm 0.01$ & -0.01 & 0.01 & 0.74 & 0.04 \\
\hline Whole Body & $\mathrm{BMC}(\mathrm{kg})$ & $2.8 \pm 0.6$ & 0.0 & 0.0 & 0.4 & 0.0 \\
\hline \multirow[t]{2}{*}{ Arms } & Fat mass (kg) & $2.3 \pm 1.1$ & 0.0 & 0.0 & 2.3 & 0.2 \\
\hline & Lean mass ( $\mathrm{kg}$ ) & $5.6 \pm 1.8$ & 0.0 & 0.1 & 1.2 & 0.3 \\
\hline \multirow[t]{2}{*}{ Legs } & Fat mass (kg) & $8.4 \pm 4.5$ & -0.1 & 0.2 & 1.3 & 0.5 \\
\hline & Lean mass (kg) & $18.2 \pm 4.0$ & -0.1 & 0.2 & 0.7 & 0.5 \\
\hline \multirow[t]{2}{*}{ Trunk } & Fat mass (kg) & $6.1 \pm 6.5$ & -0.0 & 0.3 & 1.6 & 0.7 \\
\hline & Lean mass ( $\mathrm{kg}$ ) & $24.0 \pm 4.7$ & 0.1 & 0.3 & 0.9 & 0.8 \\
\hline \multirow[t]{2}{*}{ Whole Body } & Fat mass (kg) & $23.6 \pm 11.5$ & -0.1 & 0.3 & 0.9 & 0.7 \\
\hline & Lean mass $(\mathrm{kg})$ & $51.0 \pm 10.4$ & 0.1 & 0.3 & 0.4 & 0.8 \\
\hline
\end{tabular}

RMS-SD, root mean square standard deviation; \%CV, percent coefficient of variance; LSC, ideal least significant change. 
Table 3. Whole body and regional iDXA and Prodigy enhanced bone density measurements.

\begin{tabular}{llcccc}
\hline Region & Variables & iDXA & Prodigy Enhanced & Bias & LOA \\
\hline Whole Body & BMC $(\mathrm{kg})$ & $2.8 \pm 0.6$ & $2.8 \pm 0.6$ & $0.0 \pm 0.0^{*}$ & $-0.1-0.1$ \\
& Area $\left(\mathrm{cm}^{2}\right)$ & $2255.1 \pm 234.3$ & $2219.4 \pm 236.9$ & $35.8 \pm 51.0^{*}$ & $-64.2-135.7$ \\
& BMD $\left(\mathrm{g} / \mathrm{cm}^{2}\right)$ & $1.24 \pm 0.15$ & $1.25 \pm 0.16$ & $-0.01 \pm 0.02^{*}$ & $-0.06-0.04$ \\
Hip & BMC $(\mathrm{g})$ & $36.0 \pm 7.6$ & $36.1 \pm 7.6$ & $-0.1 \pm 1.2$ & $-2.3-2.2$ \\
& Area $\left(\mathrm{cm}^{2}\right)$ & $33.2 \pm 4.0$ & $33.2 \pm 3.9$ & $0.1 \pm 0.9$ & $-1.6-1.8$ \\
\multirow{3}{*}{ Spine } & BMD $\left(\mathrm{g} / \mathrm{cm}^{2}\right)$ & $1.08 \pm 0.16$ & $1.08 \pm 0.15$ & $0.00 \pm 0.02$ & $-0.04-0.04$ \\
& BMC $(\mathrm{g})$ & $58.7 \pm 12.1$ & $59.2 \pm 12.3$ & $-0.4 \pm 1.2^{*}$ & $-2.8-1.9$ \\
& Area $\left(\mathrm{cm}^{2}\right)$ & $46.6 \pm 5.6$ & $46.6 \pm 5.6$ & $0.0 \pm 0.8$ & $-1.5-1.5$ \\
& BMD $\left(\mathrm{g} / \mathrm{cm}^{2}\right)$ & $1.25 \pm 0.15$ & $1.26 \pm 0.15$ & $-0.01 \pm 0.02 *$ & $-0.05-0.04$ \\
\hline
\end{tabular}

Mean \pm standard deviation. ${ }^{*} \mathrm{P}<0.05$. BMC, bone mineral content; $\mathrm{BMD}$, bone mineral density. 
Table 4. Whole body and regional iDXA and Prodigy enhanced body composition measurements.

\begin{tabular}{llcccc}
\hline Region & Variables & iDXA & $\begin{array}{c}\text { Prodigy } \\
\text { enhanced }\end{array}$ & Bias & LOA \\
\hline Whole body & Fat mass $(\mathrm{kg})$ & $23.6 \pm 11.6$ & $24.9 \pm 11.7$ & $-1.3 \pm 0.6^{*}$ & $-2.5-0.1$ \\
& Lean mass $(\mathrm{kg})$ & $51.0 \pm 10.4$ & $49.9 \pm 10.1$ & $1.1 \pm 0.6^{*}$ & $0.0-2.2$ \\
\multirow{2}{*}{ Arm } & Fat mass (kg) & $2.3 \pm 1.1$ & $2.5 \pm 1.2$ & $-0.3 \pm 0.2^{*}$ & $-0.6-0.1$ \\
& Lean mass (kg) & $5.6 \pm 1.8$ & $5.4 \pm 1.8$ & $0.2 \pm 0.3^{*}$ & $-0.5-0.9$ \\
Leg & Fat mass (kg) & $8.4 \pm 4.5$ & $8.9 \pm 4.5$ & $-0.5 \pm 0.3^{*}$ & $-1.1-0.1$ \\
& Lean mass (kg) & $18.2 \pm 4.0$ & $17.8 \pm 3.9$ & $0.5 \pm 0.6^{*}$ & $-0.8-1.7$ \\
Trunk & Fat mass (kg) & $12.1 \pm 6.5$ & $12.6 \pm 6.4$ & $-0.5 \pm 0.4$ & $-1.3-0.4$ \\
& Lean mass (kg) & $24.0 \pm 4.7$ & $23.6 \pm 4.4$ & $0.4 \pm 0.7^{*}$ & $-1.0-1.8$ \\
\hline
\end{tabular}

Mean \pm standard deviation, ${ }^{*} \mathrm{P}<0.05$ 